\title{
Skull Osteomyelitis
}

\author{
Myoung Soo Kim \\ Department of Neurosurgery, Seoul Paik Hospital, \\ Inje University College of Medicine \\ Republic of Korea
}

\section{Introduction}

Osteomyelitis is an inflammatory process accompanied by bone destruction and caused by an infecting microorganism. The decline of fulminant osteomyelitis of the skull from a routine event to a rare occurrence has largely paralleled the emergence of potent antibiotics. Today, osteomyelitis of the skull usually presents as a chronic process that occasionally complicates craniotomies and scalp injuries. Despite the relative infrequency of this entity, it is essential that the well-trained neurosurgeon be skilled in the recognition and treatment of this potentially dangerous condition.

In this review we describe the history of skull osteomyelitis and development of preventive methods against skull osteomyelitis after trephination. We also review postoperative skull osteomyelitis and its prevention. We discuss skull osteomyelitis associated with special conditions (skull base, fungal, pediatric, syphilitic, tuberculous osteomyelitis, and skull osteomyelitis associated with immunodeficiency virus infection (HIV)).

\section{Skull osteomyelitis}

\subsection{History of skull osteomyelitis}

\subsubsection{Skull osteomyelitis in the prehistoric period}

Trephination was performed in many parts of the ancient world and remains in use today in some traditional communities. Authors of comparative osteologic studies (Liu \& Apuzzo, 2003) have demonstrated that using primitive stone or metal instruments, prehistoric surgeons achieved an average survival rate of $50 \%-90 \%$ in patients undergoing skull trephination. Interestingly, some of these primitive surgeons covered the trephined opening with discs cut from shells or sometimes with thin gold plates (Froeschner, 1992). Although the exact incidence of infection after trephination is not known, some skulls showed infection and various stages of healing (Froeschner, 1992). The rate of infection for trephination, as represented by skeletal inflammatory reactions, was only $15 \%$. As an example, severe periostitis after the trephination resulted in the death of individuals (Gerstzen et al., 1998).

Trauma related to conflict is evident in many prehistoric cultures. In human skulls recovered from archaeological excavations, several cases of traumatic skull injury were found. One report described a man having survived an arrow injury to his forehead. 
However, he subsequently developed severe osteomyelitis, probably resulting in a generalized fatal infection (Gerstzen et al., 1998). Some skulls also showed evidence of osteomyelitis.

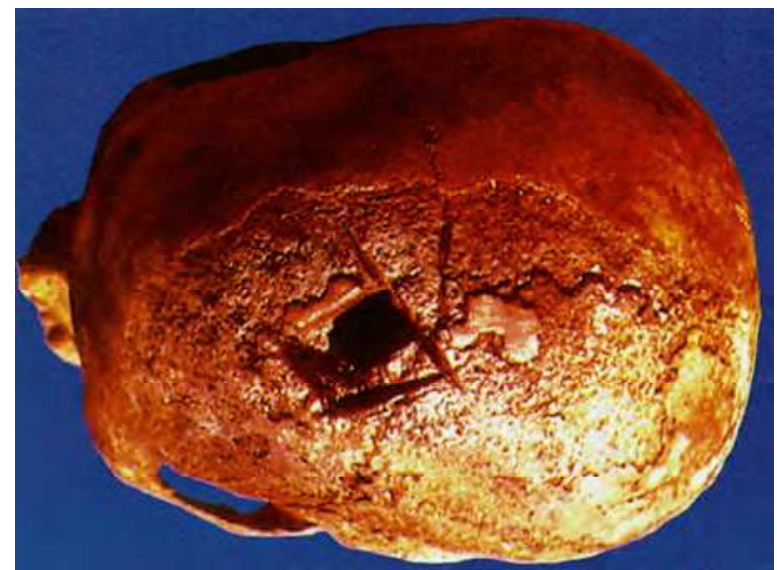

Fig. 1. A crosscut opening was made in the parietal bone of this trephined skull after a fracture. A subsequent infection resulted in severe periostitis. (Reproduced with permission from Gerszten, PC., Gerszten, E., \& Allison, MJ. (1998). Diseases of the skull in preColumbian South American mummies. Neurosurgery, Vol.42, No.5, (May 1998), pp. 11451152, ISSN 0148-396X) (Gerszten et al., 1998)

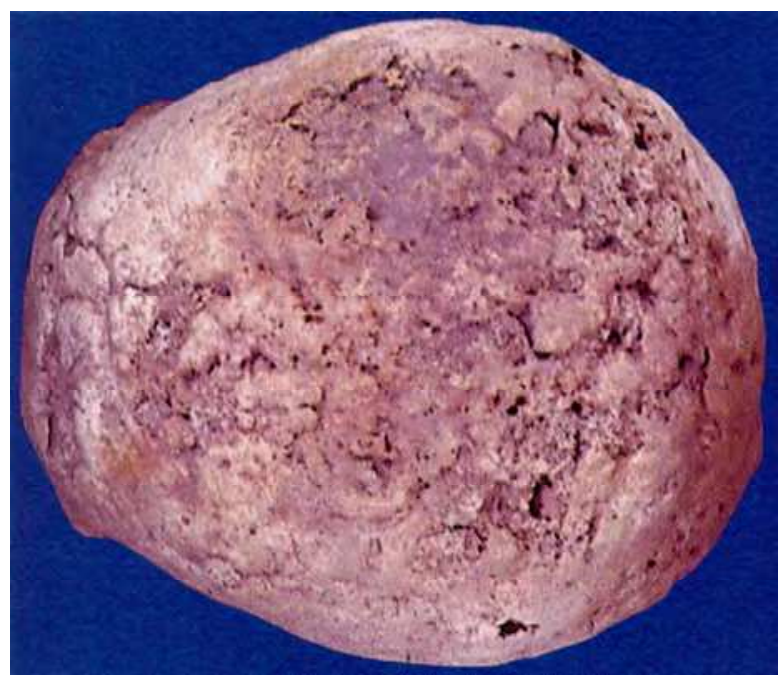

Fig. 2. Treponema peritonitis and osteitis of the calvaria in a man of the Atacameña (AD 300). He was also found to have "saber shins". (Reproduced with permission from Gerszten, PC., Gerszten, E., \& Allison, MJ. (1998). Diseases of the skull in pre-Columbian South American mummies. Neurosurgery, Vol.42, No.5, (May 1998), pp. 1145-1152, ISSN 0148-396X) (Gerszten et al., 1998). 
Bone lesions resembling tertiary syphilis caused by Treponema pallidum or another of the treponematoses have been observed in nearly every Andean culture from Peru and Chile, dating back nearly 8000 years (Gerstzen et al., 1998).

The lesions are similar in each case, with periostitis, osteitis, and osteomyelitis attacking the skull and the long bone, particularly the tibia. This tibial involvement results in the classic "saber shin". Several of the skulls observed with such lesions had been "treated" during life by repeated trephination using a scraping technique.

\subsubsection{Greek and early Byzantine period}

The intellectual evolution of neurological surgery originated in the golden age of Greece with the founding of the Alexandrian school in $300 \mathrm{BC}$. Because of both sporting injuries, in particular gladiator injuries, and wars, head injuries appear to have been plentiful, and provided opportunities to develop neurosurgical skills (Goodrich \& Flamm, 2011). In this early era of medicine, the risk of infection, lack of antiseptic technique, and minimal anesthesia prevented generations of surgeons from performing any serious or aggressive surgical intervention for head injury (Goodrich \& Flamm, 2011).

Galen of Pergamon (AD 129-200) detailed a safer and more reliable use of the trephine, and in particular argued for continuous irrigation during trephination to avoid delivering excessive heat and injury to the underlying brain (Goodrich, 2005).

Paul of Aegina (AD 625-690), trained in the Alexandrian school, was the last great Byzantine physician. His wound management was quite sophisticated for prevention of infection. He used wine (helpful in antisepsis, although this concept was then unknown) (Goodrich, 2005).

\subsubsection{Medieval Europe}

Inventive medieval surgeon Theodoric Borgognoni of Cervia (1205-1298) is remembered as a pioneer in the use of the aseptic technique - not the "clean" aseptic technique of today, but rather a method based on avoidance of "laudable pus". He attempted to discover the ideal conditions for good wound healing, and concluded that they comprised control of bleeding, removal of contaminated or necrotic material, avoidance of dead space, and careful application of a wound dressing bathed in wine (Goodrich \& Flamm, 2011). Control of bleeding, removal of contaminated or necrotic material, and avoidance of dead space are principles that can also apply in today's neurosurgical operations. He also argued for primary closure of all wounds when possible and avoiding "laudable pus" (Goodrich \& Flamm, 2011).

Lanfranchi of Milan (1250-1306) noted that the head should be shaved prior to surgery to prevent hair from getting into the wound and interfering with primary healing. Today, most neurosurgeons also shave hair before an operation. However, the time of shaving is currently controversial. When dealing with depressed skull fractures, Lanfranchi advocated putting wine into the depression to assist healing (Goodrich \& Flamm, 2011).

Guy de Chauliac (1300-1368) was clearly the most influential European surgeon of the $14^{\text {th }}$ and $15^{\text {th }}$ centuries. Chauliac also provided an interesting discussion of techniques that he devised for the treatment of head injuries. Before beginning surgery, he advocated shaving 
the head, stating that shaving of the hair would prevent it from getting into the wound and interfering with primary healing. For depressed skull fractures, Chauliac preferred to put wine-soaked cloth into the injured site to assist healing (Goodrich \& Flamm, 2011).

Leonard of Bertapalia (1380?-1460) was a prominent figure in 15th century surgery. He recommended always avoiding materials that might cause pus (Goodrich, 2005).

However, in the medieval period, the combination of a lack of anatomic knowledge and poor surgical outcomes naturally led physicians to recommend against operating on the brain, except in simple cases (Goodrich, 2005).

\subsubsection{Sixteenth century}

Ambroise Paré (1510-1590) is considered to be the father of modern surgery. Although not original to Paré, he advanced an interesting technique of elevating a depressed skull fracture using the Valsalva maneuver. This maneuver enabled the expulsion of blood and pus. He advocated debridement of wounds for good healing, emphasizing that all foreign bodies must be removed. He was skilled at removing osteomyelitis bone, incising dura, and evacuating blood clots and pus (Goodrich \& Flamm, 2011). Paré's most useful advance in surgery was the discovery that boiling oil should not be used in gunshot wounds (Goodrich, 2005).

\subsubsection{Eighteenth century}

Percival Pott (1714-1788) was the greatest English surgeon of the $18^{\text {th }}$ century. He described an osteomyelitic condition of the skull with a collection of pus under the pericranium, now called Pott's puffy tumor. In 1760, Pott described the almost constant relationship between the acute forehead swelling of frontal osteomyelitis and an underlying extradural abscess (Paramore, 1996). He felt strongly that these lesions should be trephined to remove the pus and decompress the brain. Although the frequency of Pott's puffy tumor has decreased since the introduction of antibiotics, it should be treated using the same principles.

Until early in the 19th century, surgery for pyogenic infections of the brain had an extremely high mortality rate, and was often performed by pure chance after cases of trauma. The first documented case of a successful operation was performed by François-Sauveur Morand (1697-1773) in 1752 (Guyot et al., 2006). Morand had a patient who developed otitis and subsequently mastoiditis with a temporal abscess. He trephined over the carious bone and discovered pus. Drainage of pus after two operations resulted in healing of the abscess and survival of the patient.

Benjamin Bell (1749-1806) stressed the importance of relieving compression of the brain, whether it be caused by a depressed skull fracture or pressure caused by pus or blood-a remarkably aggressive approach for this period (Goodrich, 2005). However, Lorenz Heister (1683-1758) felt that trephination in wounds involving only concussion and contusion might be too dangerous (Goodrich, 2005).

\subsubsection{Nineteenth and twentieth centuries}

Even with the best surgical technique, the patient might well die postoperatively of suppuration and infection. Fever, purulent material, brain abscess, and draining wounds all defeated the best surgeons. Surgery was revolutionized when, using concepts developed by 
Louis Pasteur, Joseph Lister introduced antisepsis into the operating room. For the first time, a surgeon, using aseptic techniques and a clean operating theater, could operate on the brain with a reasonably small likelihood of infection (Goodrich, 2005). Certainly, the development of the technique of antiseptic surgery by Lister, which stressed the treatment of the surgeon's hands with 1:20 carbolic acid, was a major advance (Leedom \& Holtom, 1993).

William Macewen (1848-1924) had operated on 21 neurosurgical cases with only three deaths and 18 successful recoveries, and considered his success to be the result of excellent cerebral localization and good aseptic technique (Goodrich, 2005).

Fedor Krause (1857-1937), like William Macewen, was a major advocate of aseptic techniques in neurosurgery (Goodrich, 2005).

William W. Keen (1837-1932), professor of surgery at Jefferson Medical College in Philadelphia, was one of the strongest American advocates for the use of Listerian techniques in surgery, advancing the concepts of surgical bacteriology, asepsis, and antisepsis. A description of Keen's surgical setup provides a contemporary view of this innovative surgeon's approach to antisepsis (Goodrich, 2005).

In 1929, Alexander Fleming (1881-1955) published a report on the first observation of a substance that appeared to block the growth of a bacterium. This substance, identified as penicillin, heralded a new era of medicine and surgery. During World War II, the use of antibiotics in the treatment of bacterial infection was perfected, reducing even further the risk of infection during craniotomy (Goodrich, 2005).

\subsection{Postoperative skull osteomyelitis}

\subsubsection{Risk factors for postoperative skull osteomyelitis}

The frequency of surgical site infections (SSIs) in a clean neurosurgical operation in randomized controlled trials is from $4.0 \%$ to $12.0 \%$ without prophylactic antibiotics and from $0.3 \%$ to $3.0 \%$ with prophylactic antibiotics (Erman, 2005).

Specific risk factors associated with postoperative skull osteomyelitis have not been reported. A variety of risk factors for SSIs in neurosurgery have been reported. SSIs may involve any or all surgical layers from the surface to deeper tissues causing superficial cellulitis, bone-flap osteomyelitis, meningitis, encephalitis, and brain abscesses (Vogelsang et al., 1998). Mollman and Haines (Mollman \& Haines, 1986) reported that the presence of a cerebrospinal fluid (CSF) leak and a concurrent non-central nervous system infection increased the estimated relative risk of infection to 13:1 and to 6:1, and use of perioperative antibiotics decreased the risk of infection to approximately $20 \%$ of control levels. Korinek (Korinek, 1997) reported the presence of a CSF leak, emergency surgery, clean-contaminated and dirty surgery, an operative time longer than 4 hours, and recent neurosurgery as independent predictive risk factors for SSIs. Other retrospective studies reported that obesity, surgical reexploration, steroid administration, and increased hospital stay for patients with infection have no relation to SSIs.

\subsubsection{Clinical manifestations and diagnosis of postoperative skull osteomyelitis}

Early diagnosis of skull osteomyelitis is very important in its treatment. However, early diagnosis is difficult. Postoperative osteomyelitis presents with findings referable to the site 
of the wound. A bone infection may cause high fever and marked local reaction and suppuration, or it may appear as a stubborn fistula.

Since progression of the disease is relatively slow and the presenting symptoms are initially subtle, the diagnosis is often made after considerable advance of the disease, which occasionally makes treatment difficult. The diagnosis of skull osteomyelitis is based primarily on the clinical findings, with data from the initial history, physical examination, and laboratory tests.

Despite the immense improvements that have taken place in medicine, we still use the same basic methods to identify infections. Blood leukocyte count and erythrocyte sedimentation rate (ESR) are methods still in use. An elevated ESR provides a useful marker to monitor the efficacy of therapy using serial determinations. C-reactive protein (CRP) is a useful indication of infection. Like ESR, it is nonspecific; its advantage is that CRP levels rise and fall rapidly after surgery, thus making it a good indicator of acute infections, recovery, and relapse (Blomstedt, 1992). Operations cause a detectable rise in CRP levels within 6 hours. The level peaks after 2 days and then falls rapidly. Daily CRP tests for all patients with an elevated temperature are recommended; a secondary increase indicates infection (van Lente, 1982). Blood cultures are obtained before initiating therapy. Bacterial culturing remains the most important method. Aspiration of the incision and bone biopsy provide the definitive diagnostic tests. Histopathological and microbiological examination of bone is the criterion standard for diagnosing osteomyelitis.

Radiographic diagnosis of osteomyelitis can be particularly difficult when there is concurrent bone destruction or repair because of a noninfectious process. Plain radiographs lack both the sensitivity and the specificity to establish a diagnosis of osteomyelitis (Tumeh et al., 1987).

Computed tomography (CT) is the best imaging modality for demonstrating bony erosion and destruction in osteomyelitis. It depicts detailed pathological changes, including focal osteopenia, subtle erosion of inner and outer tables, and gross lytic destruction. However, if bone has been altered by trauma, surgery, or infection, CT abnormalities are no longer diagnostic of active osteomyelitis. Furthermore, neither skull X-ray nor CT scan are useful for monitoring the response of osteomyelitis to therapy, because it takes several months to years for skull X-ray nor CT scan to appear normal after successful treatment (Rubin et al., 1990; Mendelson et al., 1983)

Bone scintigraphy using technetium technetium 99 and gallium citrate scans, and positron emission tomography have also been used for diagnosis, with great accuracy. These modalities can also be used to evaluate a patient's therapeutic response (Koorbusch et al., 1992). In a three-phase bone scan, initial hyperemia represents increased blood flow because of inflammation, while delayed bone images demonstrate increased radiotracer concentration. Photopenic or cold patterns may also be seen in acute hematogenous osteomyelitis. The specificity of bone scintigraphy is not sufficiently high to confirm a diagnosis of osteomyelitis in many clinical situations. On a bone scan, osteomyelitis is often not distinguished from soft tissue infections and postsurgical changes. Compared with bone scintigraphy, magnetic resonance imaging (MRI) has equivalent or greater sensitivity, specificity, and accuracy for the detection of osteomyelitis. However, MRI is usually not 
useful in monitoring the response to therapy in patients with osteomyelitis, because marrow changes caused by inflammation take 2-6 months to return to normal (Gherini et al., 1986). Gallium-67-labeled and 111In-labeled white blood cell scans are fairly sensitive, albeit nonspecific, tests whose use appears to be helpful during the follow-up period. Single photon emission CT improves the monitoring of therapy.

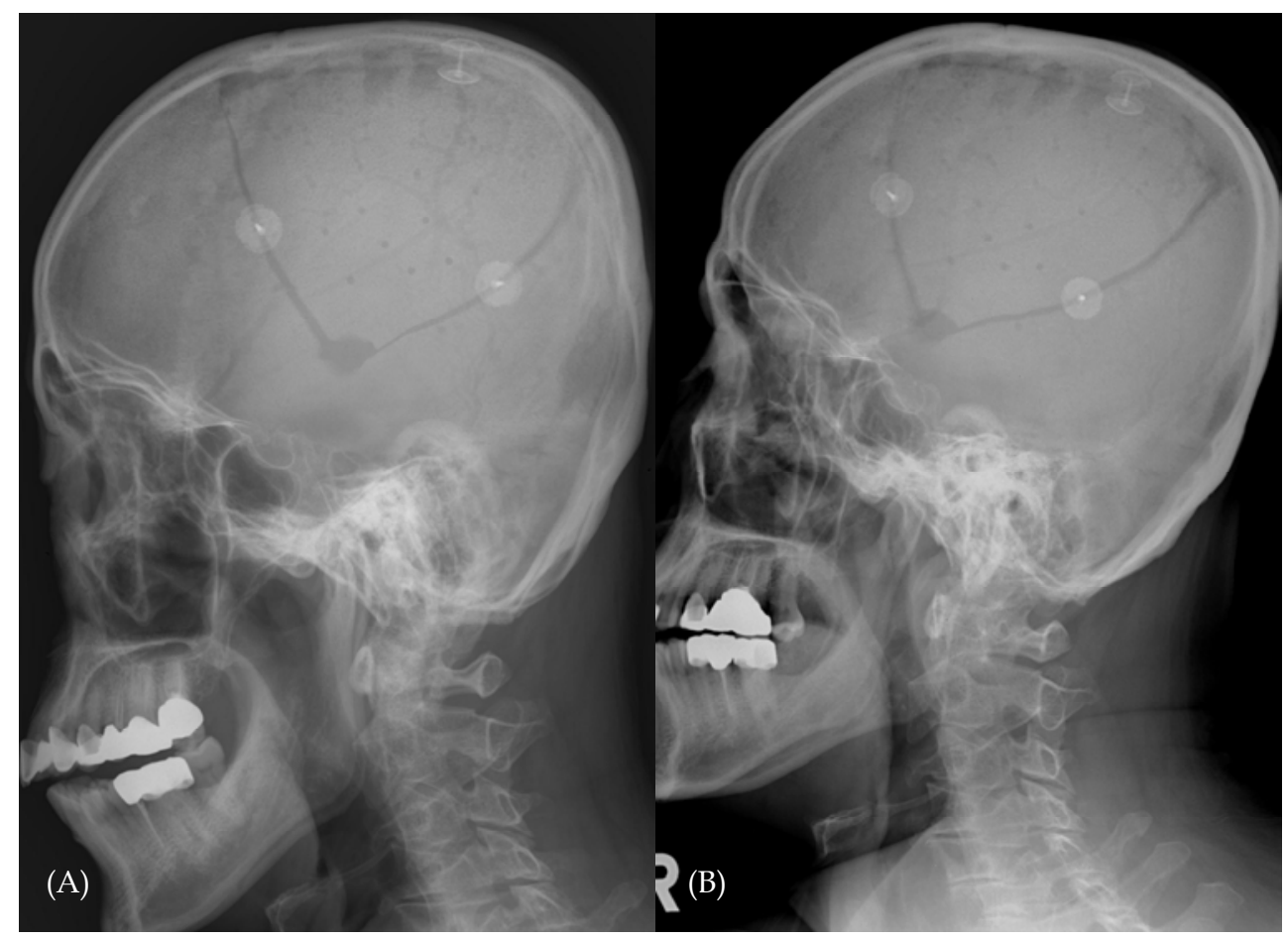

Fig. 3. Simple skull X-ray images taken 20 days (A) and 66 days (B) after a craniotomy showing the progression of an osteolytic lesion in the upper portion of the bone flap and in the adjacent surrounding bone. Staphylococcus epidermidis was cultured from blood. (Reproduced with permission from Nam, JR., Kim, MS., Lee, CH., \& Whang, DH. (2008). Linezolid Treatment for Osteomyelitis due to Staphylococcus Epidermidis with Reduced Vancomycin Susceptibility. J Korean Neurosurg Soc, Vol.43, No.6, (June 2008), pp. 307-310, ISSN 2005-3711 ) (Nam et al., 2008)

\subsubsection{Treatment}

The treatment of cranial osteomyelitis is often surgical debridement, removal of infected bone flaps, and 4-6 weeks of parenteral antibiotics. In addition, in cases arising from the sinuses or an auditory canal, surgical debridement needs to be conducted by an otologist.

Empirical therapy should be started with antibiotics broadly effective for Escherichia coli and Staphylococcus aureus (S. aureus). The antibiotics should be changed appropriately once the culture sensitivity reports are available. In advanced cases where the underlying bone is grossly eroded, a partial craniectomy may be required. 
Chou and Erickson (Chou \& Erickson, 1976) introduced a treatment with closed suction irrigation with topical antibiotics; this treatment, they claimed, may save $50 \%$ of infected bone flaps.

\subsubsection{New treatments for postoperative skull osteomyelitis with a high risk factor}

\subsubsection{Hyperbaric oxygen (HBO) therapy}

HBO therapy is used to treat a variety of infected, hypoperfused, and hypoxic wounds. Oxygen tension plays an important role in the outcome of infection (Park et al., 1992). Leukocyte bactericidal capacity is substantially impaired at low oxygen tensions often observed in wounds (Allen et al., 1997). HBO therapy increases the oxygen tension in infected tissues, including bone (Mader et al., 1980), resulting in a direct bactericidal effect of HBO treatment on aerobic organisms such as S. aureus (Korinek, 1997). HBO therapy improves host defenses and has been proven as a useful adjunct to antibiotics and surgery for the treatment of infectious wound complications after surgery in the irradiated head and neck (Neovius et al., 1997). In radiation-injured tissues, HBO therapy facilitates the formation of new capillaries, thus improving tissue oxygen tensions and host defenses, and improving osseointegration and reducing implant failure rates (Larsson et al., 2002).

The use of HBO therapy for the treatment of uncomplicated wound infections (osteomyelitis of a free cranial bone flap after craniotomy, without additional risk factors) with osteomyelitis of a bone flap is controversial. However, in complicated cranial wound infections (osteomyelitis, with or without remaining bone/acrylic flap, after craniotomy with additional risk factors, such as repeated surgery, foreign material, malignant disease, or previous radiotherapy), HBO therapy is particularly useful (Larsson et al., 2002). Infection control and establishment of the healing process can be quite rapid, and many patients continue to exhibit improvement after cessation of HBO therapy (Larsson et al., 2002).

\subsubsection{One-stage reconstruction of cranial defects using a titanium mesh plate enclosed in an omental flap}

Treatment of chronic cranial osteomyelitis is difficult. Asai et al. (Asai et al., 2004) developed a reconstructive technique for osteomyelitis-related cranial defects that fills the dead space with an omental flap and uses a titanium mesh plate as a structural element.

Cranial defects have been reconstructed with split rib, split calvarial bone, biocompatible osteoconductive polymers, and by many other methods. However, if there is an infection at the site, autogenous bone should be selected as a reconstructive material, even though autogenous bone itself may become infected. The advantages of using an omental flap are that there is sufficient tissue volume to cover a large wound, it can be cut to any space, and it shapes relatively large blood vessels, making vascular anastomoses easier to perform. Titanium mesh plates make an excellent prosthesis in many ways, but carry the risk of exposure associated with thinning of overlying skin (Asai et al., 2004). Asai et al. (Asai et al., 2004) described the first case of an omental flap-mesh-omental flap "sandwich". To reduce the risk of prosthesis exposure and infection, Asai et al.'s technique places the omental flap both superficial and deep to the titanium mesh plates, thus vascularizing the graft. The use of an omental flap has several advantages in cranial reconstruction, and its flexible consistency facilitates the obliteration of dead space because it adapts to the size and shape of the defect (Asai et al., 2004). 


\subsubsection{Vacuum-Assisted Closure (VAC)}

VAC therapy was introduced by Argenta and Morykwas in 1997 (Argenta \& Morykwas, 1997) and has been in routine clinical use for the treatment of difficult wounds. The mechanism of treatment is exposure of the wound bed to negative pressure, resulting in removal of edema fluid, improvement in the blood supply, and stimulation of cellular proliferation of reparative granulation tissue (Subotic et al., 2011). Reconstruction of scalp and calvarial defects can be challenging because of the poor vascularity of the cortical bone. The aims of VAC therapy are the formation of new granulation tissue, wound cleansing, and bacterial clearance.

Subotic et al. (Subotic et al., 2011) reported successful treatment of chronic scalp wounds with exposed dura using VAC. The VAC device is feasible for use in the treatment of scalp wounds with exposed dura and chronic infection to create a setting for wound closure, e.g., secondary healing and skin transplantation (Subotic et al., 2011).

\subsubsection{Preservation of bone flap in patients with post-craniotomy infections}

The standard care for the management of post-craniotomy wound infections consists of operative debridement and removal of the devitalized bone flap followed by delayed cranioplasty performed several months later. This strategy, although successful in treating most patients, adversely affects patient satisfaction by necessitating an additional surgical procedure for cranioplasty, as well as leaving a cosmetic deformity and lack of brain protection before cranioplasty can be performed.

Standard operative debridement for preservation of the bone flap consists of reopening of the wound and re-elevation of the bone flap. All visible suture material and hemostatic agents are removed. The purulent material is cultured and analyzed for anaerobic and aerobic organisms, and for antibiotic sensitivities. Necrotic and purulent debris is removed by mechanical debridement and copious irrigation with bacitracin solution followed by saline. The bone flap is vigorously scrubbed and soaked in Betadine solution. In no instance is the bone flap autoclaved, and the bone edges are not routinely drilled. Hemostasis is achieved with the aid of bipolar cautery and a hemostatic agent such as Avitene (Avicon, Fort Worth, TX, USA) or FloSeal (Fusion Medical Technologies, Fremont, CA, USA) (J.N. Bruce \& S.S. Bruce 2003).

Simple operative debridement is sufficient in patients with uncomplicated post-craniotomy infections, making it unnecessary to discard bone flaps and perform later cranioplasties. Even patients with risk factors such as prior surgery, skull base procedures, chemotherapy, or radiotherapy can be successfully treated using this strategy in most cases. However, patients with craniofacial surgery involving the nasal sinuses are at higher risk and might be best treated with bone flap removal and delayed cranioplasty (J.N. Bruce \& S.S. Bruce 2003). J.N. Bruce and S.S. Bruce (J.N. Bruce \& S.S. Bruce 2003) reported the highly favorable results of a prospective study in which aggressive surgical debridement was performed to preserve bone flaps without cranioplasty in patients who had post-craniotomy wound infections.

\subsubsection{Prevention of neurosurgical infection}

Specific methods for prevention of postoperative skull osteomyelitis have not been reported. A variety of methods for prevention of SSIs in neurosurgery have been reported. 
Leaper (Leaper, 1995) reviewed the principles given for prevention such as an emphasis on surgical skill to minimize tissue damage and residual hematoma formation that could also apply to neurosurgery. In compound depressed skull fractures, the most effective way of avoiding subsequent meningitis, abscess, or empyema is rapid and thorough debridement and elevation of the fracture.

For antimicrobial prophylaxis, Baker (Baker, 1994) performed a meta-analysis to determine with more confidence whether antimicrobial prophylaxis for craniotomy is effective. He concluded that there was a significant advantage of antimicrobial prophylaxis over placebo, but no significant differences between regimens that did or did not cover Gram-negative organisms or between single- and multiple-dose regimens. The impact of prophylaxis noted in clean procedures may be diminished in contaminated procedures because of the larger biomass of contaminating bacteria and hence the need for additional measures such as debridement with the latter.

The general surgical literature contains significant evidence for decreased wound infection rates with careful skin preparation, but without shaving (Alexander et al., 1983). That shaving the day before operation causes higher rates of infection is well known, but even same-day shaving or clipping have been implicated. Surgery without shaving the scalp is technically feasible, and does appear to reduce the infection rate (Hosein et al., 1999).

\subsection{Skull Base Osteomyelitis (SBO)}

SBO has been described most often as a complication of malignant otitis externa (MOE) secondary to Pseudomonas aeruginosa (P. aeruginosa) infection (Chandler, 1989). Increasing age, diabetes mellitus, and microvascular disease are common risk factors (Rothholtz et al., 2008). $\mathrm{SBO}$, however, may also occur in the absence of MOE and with pathogens other than $P$. aeruginosa, including fungi. Fungal SBO has been reported to be mostly caused by Aspergillus species, and less commonly by Scedosporium spp. (Lee et al., 2008; Stodulski et al., 2006).

Early diagnosis, identification of the causative pathogens, prompt initiation of appropriate antimicrobial or surgical therapies, and continuation of therapy for an adequate period are essential when managing SBO. Identification of the pathogen often requires surgical biopsy. Because this may be delayed for medical or technical reasons, clinical features or risk factors that discriminate between SBO caused by bacterial and fungal infections could guide selection of empiric antimicrobial therapy pending a definitive diagnosis (Blyth et al., 2011).

\subsubsection{Typical type (SBO secondary to MOE)}

In 1959, Meltzer and Keleman (Meltzer \& Keleman, 1959) reported a case of external otitis caused by $P$. aeruginosa in a patient with poorly controlled diabetes mellitus who later died despite progressive medical and surgical treatment. The term "MOE" was introduced by Chandler (Chandler, 1968) in 1968 when he published a review of his personal experience with 13 patients. He detailed what are now considered the classical physical examination and histology findings and deduced the currently accepted pathophysiology. However, in contrast with today's therapies, he believed that radical surgical debridement offered the only chance of cure. Advances in imaging and antibiotic therapy have changed this belief; these advances and greater awareness of the disease have brought a dramatic improvement in the prognosis of MOE (Sreepada \& Kwartler, 2003). 
The most common predisposing factor in the development of temporal bone osteomyelitis secondary to MOE is diabetes mellitus (Chandler, 1989). Driscoll et al. (Driscoll et al., 1993) found that cerumen from the ears of patients with diabetics had a higher average $\mathrm{pH}$ compared with that from the ears of nondiabetics, and they postulated that such alkaline $\mathrm{pH}$ could provide a beneficial environment for bacterial overgrowth. Diabetic patients' increased predisposition to temporal bone osteomyelitis is also because of their increased susceptibility to microangiopathic changes and an altered immune response (Alva et al., 2009).

SBO is a serious, life-threatening condition seen most commonly in elderly diabetic or immunocompromised patients. Usually, it is a complication of otitis externa when repeated episodes fail to resolve with topical medication and aural cleansing. Pain may become worse, granulation tissue is seen within the auditory canal, the bone of the external auditory canal becomes involved, and cranial neuropathies may arise. These patients usually have only minimal constitutional symptoms. The typical patient has headaches and ear pain as the primary complaints. Cranial nerve palsies occur less frequently and indicate advanced disease. This MOE can be difficult to treat, but it is a reasonably well-recognized clinical entity that should be straightforward to diagnose in an ears, nose, and throat setting. This condition has been described most often as complication of MOE secondary to P. aeruginosa infection. $P$. aeruginosa is by far the commonest pathogen implicated in MOE, being responsible for $50 \%-98 \%$ of all cases. Fungal SBO is increasingly reported in the literature (Marr et al., 2002; Roden et al., 2005).

The warning signs of temporal bone osteomyelitis followed as: deep pain (temporal, parietal, postauricular, or retro-orbital); intermittent, foul otorrhea and spiking fever; preauricular cellulitis; woody induration of the pinna; chronic mastoid cutaneous fistula; fibrotic mastoid granulation tissue; intermittent facial twitching suggestive of facial canal dehiscence; and persistent leukocytosis and an elevated ESR. It is widely accepted that clinical suspicion of MOE should be heightened when otalgia persists in adequately treated patients with otitis externa. The diagnosis is based on a combination of clinical findings, history, imaging, microbiology, and histology (Cohen \& Friedman, 1987). Identification of skull base osteitis in imaging studies seems to be an indispensable indicator. However, imaging studies are particularly useful in determining the extent of the inflammatory process. In such cases, deep surgical biopsies are mandatory, and are now the main indication for surgery in patients with suspected MOE (Rubin et al., 2004). The imaging studies lack specificity in differentiating MOE from diseases with similar symptoms, such as nasopharyngeal and skull base tumors. A bacterial or a fungal species should always be isolated. The role of histology is mainly to differentiate this entity from malignant tumor. CT defines the location and extent of the disease at initial evaluation (Alva et al., 2009). MRI has the advantage of better soft tissue discrimination than CT, and is particularly useful for assessing soft tissue planes around the skull base and abnormalities of the medullary cavity of bone. MRI features that are highly sensitive but nonspecific for osteomyelitis include marrow T1 hypointensity and T2 hyperintensity (Chang et al., 2003).

Treatment for osteomyelitis consists of broad-spectrum antibiotics for not less than 3 months, along with surgical debridement and wide meatoplasty (Alva et al., 2009). Antimicrobial therapy in SBO is targeted to eradication of the causative pathogen. The role 
of surgical resection is also likely to be influenced by a pathogen. Aggressive surgical debridement is recommended in fungal SBO, but is probably unnecessary in patients with bacterial SBO.

Early diagnosis is very important, because MOE may not always be slow and gradual, but sometimes rapid and fulminant. Some patients present with a venous sinus thrombosis, cerebral infarct, or cerebral abscess (Vourexakis et al., 2010). Other central nervous system complications, such as meningitis, have also been reported (Sreepada \& Kwartler, 2003).

\subsubsection{Atypical type (central SBO)}

Atypical SBO is an uncommon condition that is potentially life threatening if not promptly recognized and properly treated (Chandler et al., 1986). Atypical SBO occurs much less frequently and does not begin with otitis externa (Chang et al., 2003). These patients may have headaches as the initial symptom and only later develop cranial abnormalities (Grobman et al., 1989). Whereas MOE primarily affects the temporal bone, central or atypical SBO can be seen affecting the sphenoid and occipital bone, often centered on the clivus, and can be considered a variant of MOE (Chang et al., 2003).

It can present with headache and a variety of cranial neuropathies, often a combination of abducens and lower cranial nerve neuropathies. The imaging findings are of particular concern because they frequently mimic malignancy, which makes accurate histological diagnosis all the more important. However, once diagnosed and treated with appropriate antibiotics, it is one of the few times when cranial nerve palsies can be seen to resolve. Several potentially serious complications can arise as a result of SBO, including cranial neuropathy, soft tissue involvement of the cavernous sinus with or without cavernous sinus thrombosis, and meningeal and brain parenchymal extension. Cranial nerve involvement is commonly seen because of the proximity of the clivus to the brain stem, basal cisterns, cavernous sinuses, and skull base foramina (Chang et al., 2003). Other complications of SBO reported in the literature have included epidural abscess of the cervical spine as a result of the spread of infection through the prevertebral space (Azizi et al., 1995) and petroclival abscess (Hoistad \& Duvall, 1999).

The imaging findings are of particular interest. The bone erosion and marrow infiltrate of the basiocciput or petrous apex, as well as mass-like soft tissue swelling below the skull base, often raises concerns that there is an underlying malignant process, such as a nasopharyngeal carcinoma or skull base metastases. Imaging of the skull base in the setting of cranial neuropathy and probable infection is best accomplished with MRI. MRI has the advantage of superior soft tissue discrimination without the beam-hardening artifacts of CT. Clival enhancement can be seen with both infectious and neoplastic processes, but it should not be observed under normal circumstances. The use of fat suppression on postgadolinium study is of course necessary to assess skull base enhancement accurately (Chang et al., 2003). Other imaging techniques can help support the diagnosis of SBO. Technetium scans may be helpful for initial diagnosis, although they may remain "hot" for months following resolution of infection (Seabold et al., 1995). Gallium scan abnormalities have been shown to be useful to monitor response to treatment and evaluate recurrence (Grobman et al., 1989). 
A tissue-sampling procedure is often required for definitive diagnosis of this condition, because the imaging appearance alone is highly suggestive but nonspecific for SBO. Diagnosis is made by endoscopic sphenoidotomy or open craniotomy. Potentially complicating the diagnosis is the fact that a low burden of infectious organisms within the clival bone or preclival soft tissue can lead to a false-negative biopsy (Chang et al., 2003). New modalities such as MRI-guided biopsy of soft tissue surrounding the skull base may prove to be useful under these circumstances (Kacl et al., 1999). An important point is to always send biopsy material for microbiological analysis as well as histology; ultimately, this may lead to the correct diagnosis. In this lesion, biopsy is inevitably required both to ensure the absence of malignancy and to aid subsequent microbiological advice.

\subsubsection{Fungal SBO}

Fungal SBO involves an immunocompromised host, prior antibiotic therapy, and steroid therapy. In contrast with bacterial SBO, fungal SBO has not been definitively associated with diabetes mellitus. Invasive fungal disease is usually caused by $A$. fumigatus and less commonly by A. flavus (Bickley et al., 1988). Given the rarity of fungal SBO, it is not surprising that almost all prior cases involving a several-week delay in diagnosis are secondary to misdiagnosis of necrotizing external otitis (Hanna et al., 1993).

Fungal SBO is increasingly reported in the literature. This apparent rise may reflect the increasing use of immunosuppressive therapies in parallel with the rise of other forms of invasive fungal disease (Roden et al., 2005). Importantly, however, fungal SBO may also occur in immunocompetent individuals (Shelton et al., 2002) and should be considered in all patients presenting with symptoms or signs of SBO, especially given evidence from other forms of invasive fungal disease that a delay in antifungal therapy results in increased mortality (Chamilos et al., 2008). Fungal SBO is often only considered following failure of antibacterial therapy (Kountakis et al., 1997). In a study by Blyth et al. (Blyth et al., 2011), $55 \%$ of patients with fungal SBO were treated with antibacterial drugs for a median of 5 weeks prior to diagnosis.

Most cases of fungal SBO result from Aspergillus or Scedosporium spp., reportedly arising from the contiguous spread of ear infection (Shelton et al., 2002). Patients with fungal SBO were more likely to have underlying chronic sinus disease, symptoms attributable to invasive sinus infection (sinofacial pain, periorbital swelling, nasal stuffiness/discharge), but with a relative paucity of features attributable to ear infection (Blyth et al., 2011).

Definitive diagnosis of fungal SBO usually requires pathological demonstration of tissue invasion. Technetium bone scan is very sensitive for osteomyelitis, and this is strongly positive. Gallium scan is also positive, further supporting the diagnosis of osteomyelitis. CT reveals definite evidence of bone destruction (Shelton et al., 2002) (Figs. 4 and 5) (Lee et al., 2005).

Calcium oxalate production has been frequently noted with $A$. niger infection. The presence of calcium oxalate crystals may assist in early diagnosis before the return of culture results in this rare clinical entity (Shelton et al., 2002). Early diagnosis, identification of the causative pathogen, prompt initiation of appropriate antimicrobial or surgical therapies, and continuation of therapy for an adequate period are essential when managing SBO. 

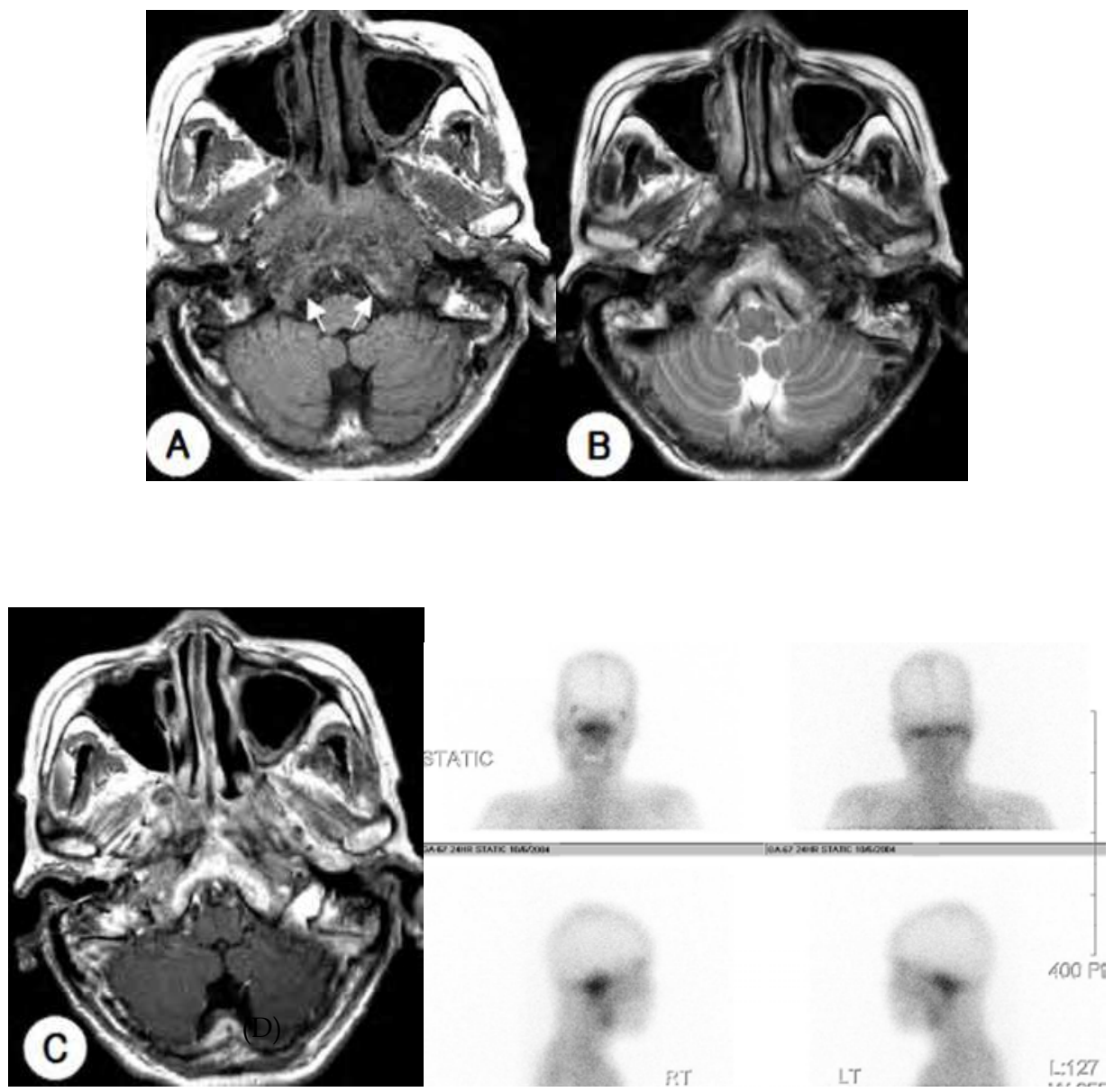

Fig. 4. (A) On axial T1-weighted MR imaging, a high signal intensity of normal fatty marrow within clivus (arrows) is replaced by inhomogeneous low signal intensity. Abnormal soft tissue intensity signals infiltrate the nasopharynx submucosally and adjacent parapharyngeal space. (B) On axial T2-weighted MR imaging, nasopharyngeal soft tissues show low signal intensity compared with normal muscle. In addition, there is fluid in the mastoid air cells. (C) With Gd-enhancement, nasopharyngeal soft tissues and prevertebral muscles show diffuse enhancement. (D) A gallium scan shows intense uptake in the right petrous temporal bone. (Reproduced with permission from Lee, SS., Son, JY., Lee, JH., \& Kim, OK. (2005). A Case of Invasive Fungal Sinusitis Accompanied with Inflammatory Pseudotumor in Skull Base. Korean J Otolaryngol-Head Neck Surg, Vol.48, No.9, (September 2005), pp. 1173-1176, ISSN 1225-035X) (Lee et al., 2005). 


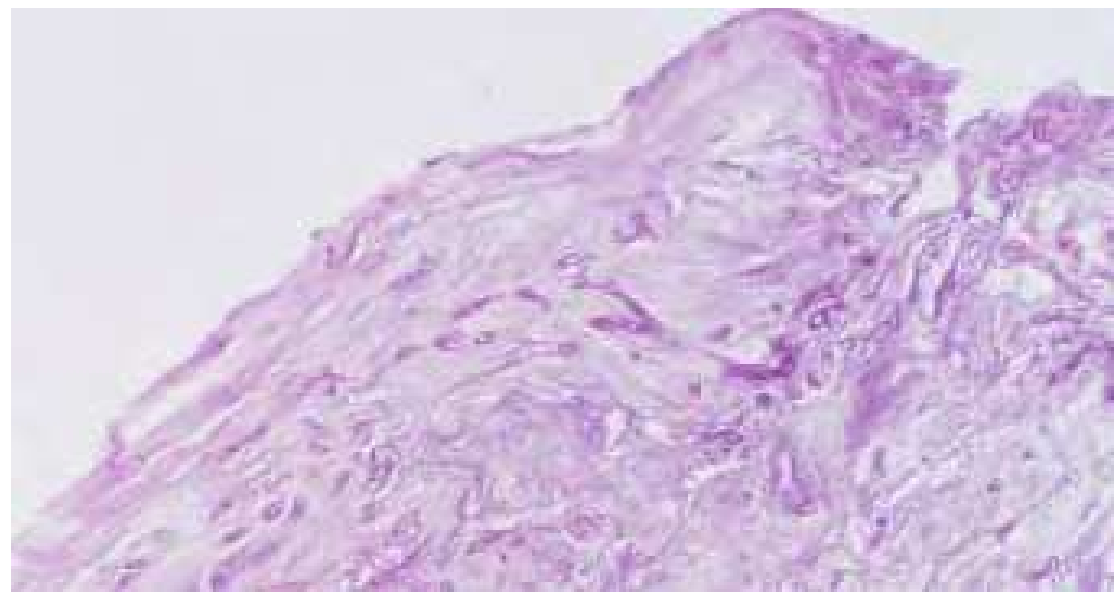

Fig. 5. (A)

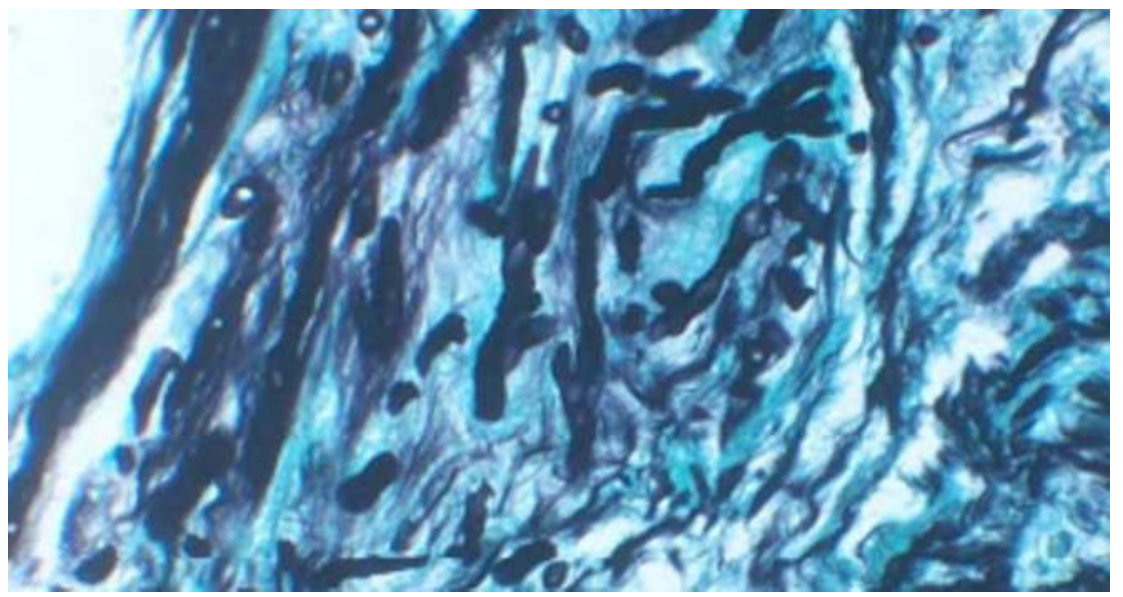

Fig. 5. (B) 


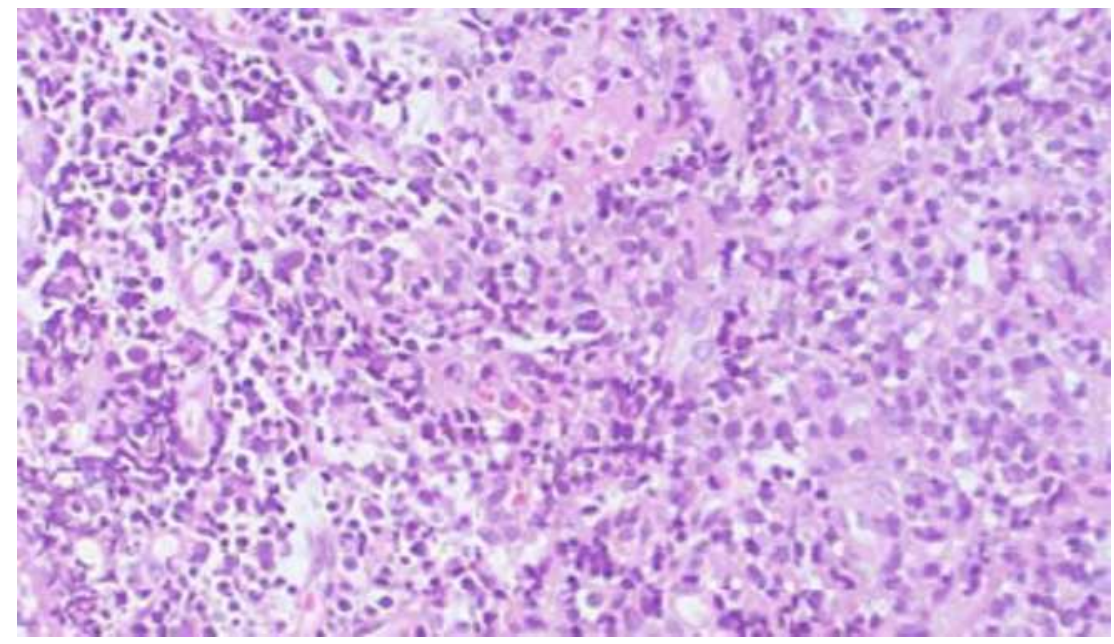

Fig. 5. (C)

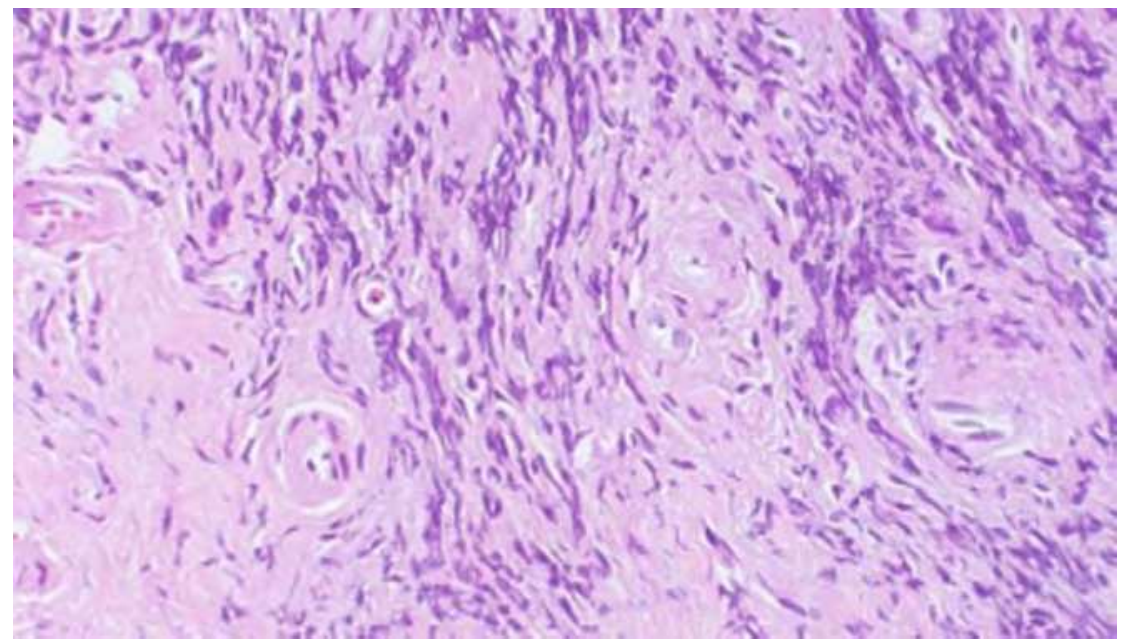

Fig. 5. (D)

Fig. 5. Histological findings show fungal hyphae compatible with Aspergillus within the mucosa of the sphenoid sinus (A, B). (A: hematoxylin and eosin, $\times 200, B$ : Gomori's methenamine silver, $\times 400)$. Histological findings of a nasopharyngeal biopsy $(C, D)$. C: There is diffuse infiltration of inflammatory cells, especially lymphocytes and plasma cells (hematoxylin and eosin, original magnification $\times 200$ ). D: Increased fibroblastic activity and collagen deposition are noted in submucosa adjacent to infiltrated inflammatory cells (hematoxylin and eosin, $\times 200$ ). (Reproduced with permission from Lee, SS., Son, JY., Lee, JH., \& Kim, OK. (2005). A Case of Invasive Fungal Sinusitis Accompanied with Inflammatory Pseudotumor in Skull Base. Korean J Otolaryngol-Head Neck Surg, Vol.48, No.9, (September 2005), pp. 1173-1176, ISSN 1225-035X) (Lee et al.., 2005) 
Antimicrobial therapy in SBO is targeted to eradication of the causative pathogen. Because $P$. aeruginosa infection predominates in most case series of bacterial SBO, initiation of antibiotics with activity against $P$. aeruginosa is appropriate pending microbiological diagnosis (Blyth et al., 2011). Blyth et al. (Blyth et al., 2011) recommended the use of regimens including high-dose amphotericin $\mathrm{B}$ formulations pending definitive diagnosis. Aggressive surgical debridement is recommended in fungal SBO (Stodulski et al., 2006) but is probably unnecessary in patients with bacterial SBO (Blyth et al., 2011).

The diagnosis of invasive fungal SBO requires a high index of suspicion as it is often misdiagnosed as bacterial otitis externa.

\subsection{Pediatric skull infection}

Osteomyelitis of the skull in pediatric patients is most common complication of a compound skull wound following either surgery or trauma. It may also occur in the frontal bone secondary to sinus infection or in the parietal and temporal bones from ear infection. Osteomyelitis may develop in the skull of a newborn as a complication of an infected scalpwound from the use of forceps or secondary to intrauterine monitoring. Rarely, it occurs opportunistically in a child with a suppressed immune mechanism, and may be the result of a fungal infection. In this section, we discuss unique types of skull osteomyelitis seen in the pediatric patient.

\subsubsection{Skull osteomyelitis complicating infected cephalohematoma}

Osteomyelitis of the skull in the neonatal period is very rare. All reported cases are secondary to an infected cephalohematoma (Miedema et al., 1999), and complications of infected cephalohematoma, such as osteomyelitis or epidural abscess, may develop. Placement of a scalp electrode, scalp-vein line insertion, or trauma to the scalp by instruments are thought to be common routes for the introduction of infection (Miedema et al., 1999).

However, no source of infection can be identified in $50 \%$ of cases, so cephalohematoma should be considered as a potential site of infection, even without a history of scalp trauma (Miedema et al., 1999). Prasad et al. (Prasad et al., 2011) described one case of skull osteomyelitis without a history of scalp trauma. They reported that delayed swelling was first noted on the tenth day after birth, which is very unusual for a cephalohematoma. Their explanation is as follows; a small cephalohematoma that remained unnoticed may have been present at birth, until it was infected and started to progressively increase in size, or osteomyelitis resulted from hematogenous spread (Prasad et al., 2011).

The most common pathogens in infected cephalohematomas are E. coli and S. aureus (Chang et al., 2005; Goodwin et al., 2000). CT is the best imaging modality to demonstrate bony erosion and destruction in osteomyelitis complicating infected cephalohematoma (Chan et al., 2002). It depicts detailed pathological changes, including focal osteopenia, subtle erosion of inner and outer tables, and gross lytic destruction.

Management consists of surgical drainage, together with a prolonged course of intravenous antibiotics. Empirical therapy should be started with antibiotics covering for E. coli and $S$. aureus. The antibiotics should be changed appropriately once the culture sensitivity reports 
are available. Typically, osteomyelitis caused by infected cephalohematoma requires 4-6 weeks of intravenous antibiotics (Chang et al., 2005). In advanced cases, where the underlying bone is grossly eroded, a partial craniectomy may be required (Chan et al., 2002).

\subsubsection{Pott's puffy tumor in children}

Pott's puffy tumor was first described in 1760 by Percival Pott, a surgeon at St. Bartholomew's Hospital in London, as "a puffy, circumscribed, indolent tumor of the scalp and a spontaneous separation of the pericranium from the skull under such tumor" in observation of the natural course of head trauma. Currently, it is defined as a foreheadlocalized swelling with overlying subperiosteal abscess and osteomyelitis of the frontal bone (Bambakidis \& Cohen, 2001; Tattersall, 2002). It was considered a rare entity in the postantibiotics era, and the majority of reported cases were adolescents and young adults. The incidence of Pott's puffy tumor showed a trend of increasing incidence in the review of articles (Rao et al., 2003; Tattersall, 2002). This may be attributed to partial antibiotics treatment for chronic sinusitis, and delayed diagnosis of potentially serious complications of frontal sinusitis (Rao et al., 2003).

Pott's puffy tumor is often associated with antecedent frontal sinusitis, and less commonly with trauma (Rao et al., 2003; Karaman et al., 2008). Other rarer risk factors for Pott's puffy tumor include osteocartilaginous necrosis secondary to chronic intranasal cocaine abuse, dental sepsis, or delayed complications of neurosurgery (Rao et al., 2003; Karaman et al., 2008).

Gradually tendered tumefaction of the scalp at the forehead is a typical sign. Osteomyelitis arising from paranasal sinusitis presents with the findings of the underlying process (nasal discharge, localized pain, and tenderness over the affected sinus, headache, localized edema, and inconsistently, fever). The initial symptoms and signs of Pott's puffy tumor often exhibit inconspicuously, which represents frontal sinusitis. Nasal obstruction and fever are less common. Acute worsening of symptoms, particularly headache and fever, or presenting with signs of increased intracranial pressure (nausea, vomiting, lethargy), periorbital complaints, or failure of resolution of symptoms with antibiotics treatment warrant image evaluation to look for silent intracranial involvement, even in the absence of neurological symptoms (Bambakidis \& Cohen, 2001; Rao et al., 2003; Karaman et al., 2008). Intracranial involvement including meningitis, subdural empyema, cerebral abscess, epidural abscess, and rarely cavernous or superior sagittal sinus thrombosis and epidural frontocutaneous fistulas has been reported (Forgie \& Marrie, 2008; Gupta et al., 2004; Yucel \& Ogretmenoglu, 1998).

CT scan is the diagnostic modality for Pott's puffy tumor, but MRI is the criterion standard for the diagnosis of intracranial complications (Durur-Subasi et al., 2008).

Because of the high incidence of intracranial complications, both imaging studies should be performed when Pott's puffy tumor is suspected, especially for those having neurological symptoms or periorbital involvement.

The use of antibiotics should be prolonged for at least 6-8 weeks postoperatively (Bambakidis \& Cohen, 2001; Brook, 2009). In consideration of rapid intracranial expansion, aggressive debridement should be prompt, and reoperation is often needed to evacuate the abscess of sinusitis, the subperiosteal abscess, the infected bone, and the epidural or subdural abscess, because the septic material may continuously disperse, which will lead to recurrence or disease progression. 


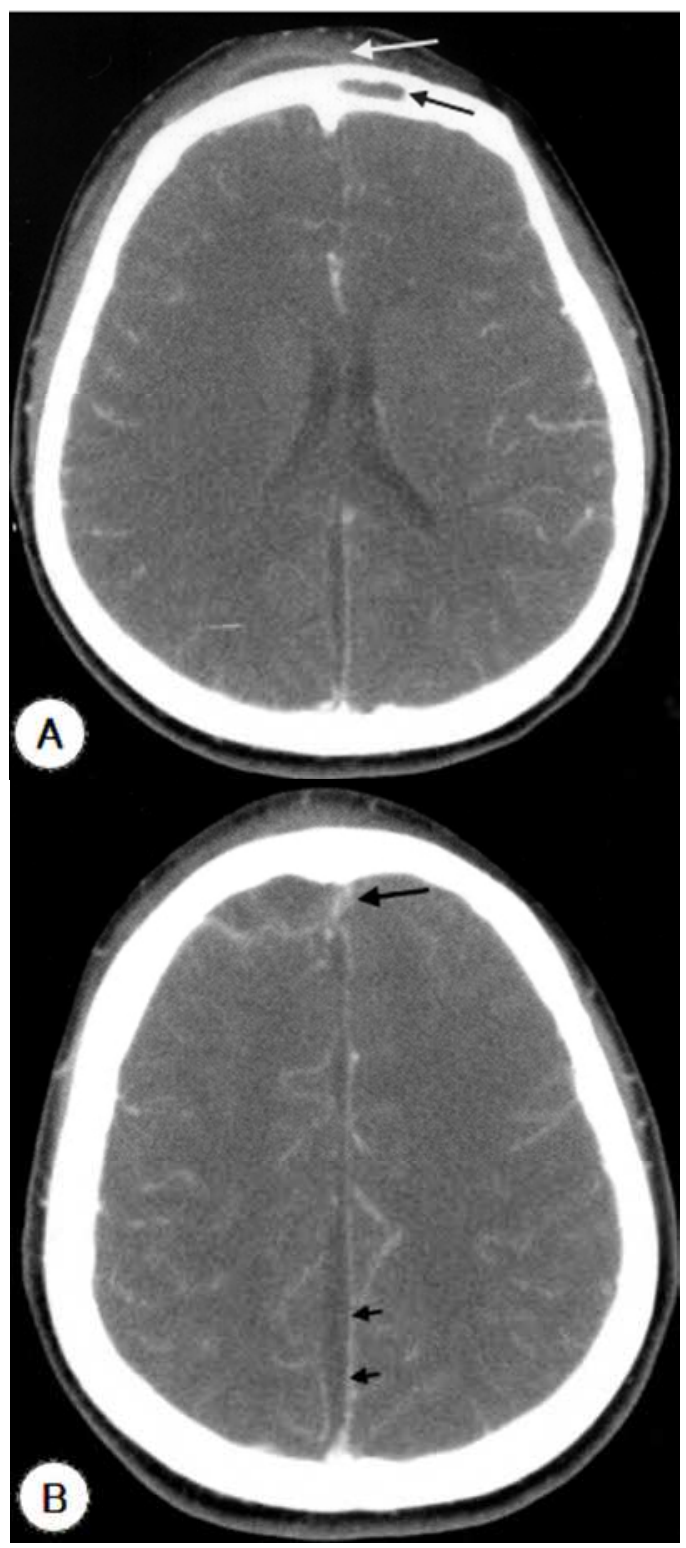

Fig. 6. Enhanced axial CT images of Pott's puffy tumor in a 12-year-old girl. A: Left frontal sinusitis (black arrow) and right subperiosteal abscess (white arrow). B: Right epidural abscess (black arrow) and subdural empyema along the falx cerebri (arrowheads).

(Reproduced with permission from Lim, HW., Jang, YJ., Lee, BJ., \& Chung, YS. (2006). A Case of Pott's Puffy Tumor as a Complication of Contralateral Frontal Sinusitis. Korean J Otolaryngol-Head Neck Surg, Vol.49, No.1, (January 2006), pp. 109-112, ISSN 1225-035X) (Lim et al., 2006) 


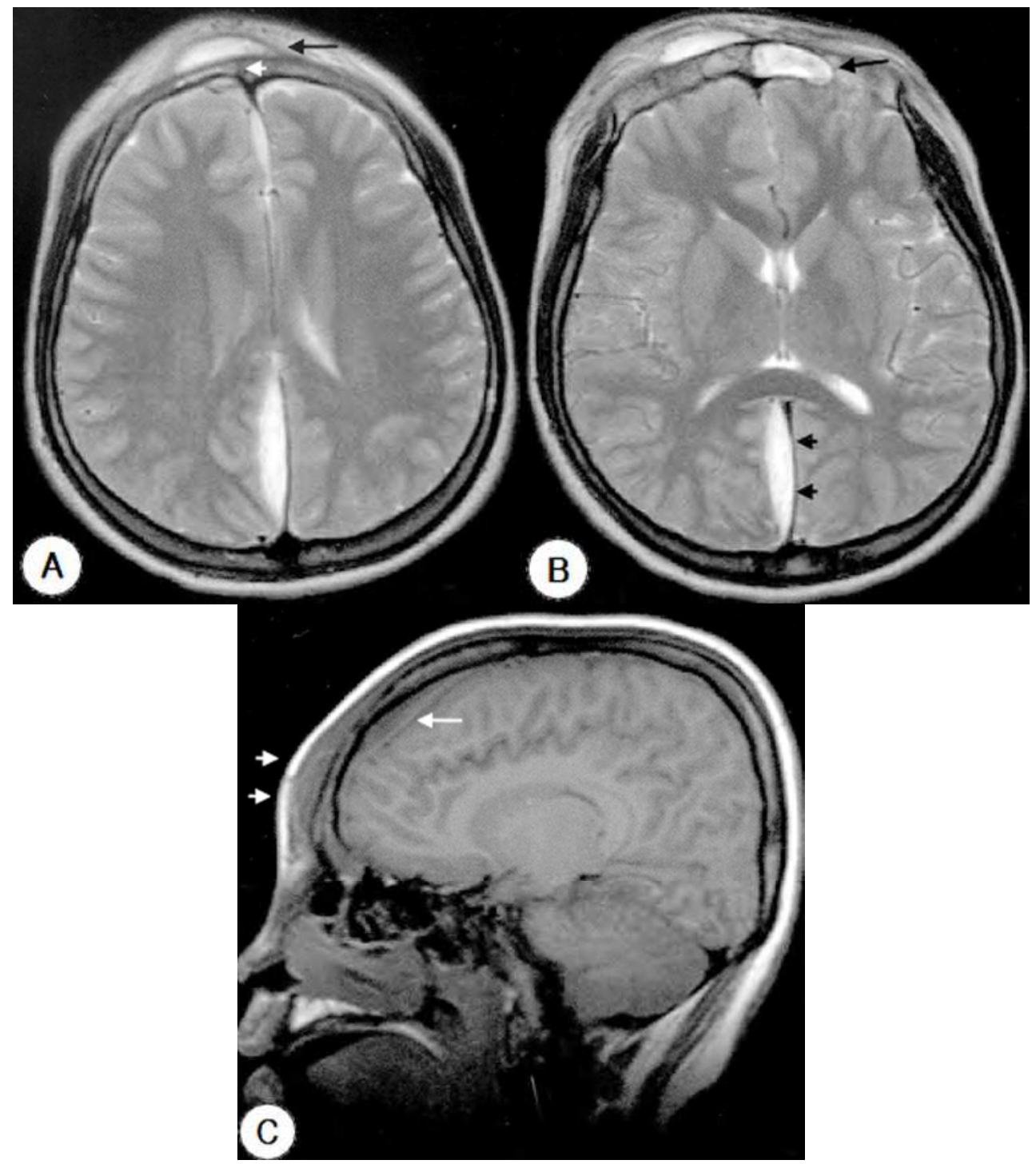

Fig. 7. Magnetic resonance images of Pott's puffy tumor in a 12-year-old girl. A: T2weighted axial MR finding of osteomyelitis. Note the high signal lesion of the right frontal bone marrow (arrowhead) under the right subperiosteal abscess (black arrow). B: T2weighted axial MR. Left frontal sinusitis (black arrow) accompanied with right subperiosteal abscess and subdural empyema along the falx cerebri (arrowheads). C: T1-weighted sagittal MR. Note the swelling of the forehead, and subperiosteal abscess (arrowheads) and epidural abscess formation (white arrow). (Reproduced with permission from Lim, HW., Jang, YJ., Lee, BJ., \& Chung, YS. (2006). A Case of Pott's Puffy Tumor as a Complication of Contralateral Frontal Sinusitis. Korean J Otolaryngol-Head Neck Surg, Vol.49, No.1, (January 2006), pp. 109-112, ISSN 1225-035X) (Lim et al., 2006) 


\subsubsection{Clival osteomyelitis}

Osteomyelitis of the clivus is an uncommon condition in the pediatric population. Previous authors have suggested various other causes of clivus osteomyelitis, which include direct spread of an infectious process involving the paranasal sinuses or adjacent bones of the skull base (Rusconi et al., 2005). Prabhu et al. (Prabhu et al., 2009) proposed that the fossa navicularis magna can be a potential source of transmission of infection through the skull base from the lymphatic tissue in the pharynx. The presence of an emissary vein in addition to lymphatics in the fossa navicularis magna may be a potentiating factor for the unusual route of spread of infection through this skull base foramen (Prabhu et al., 2009). Anecdotal cases have been reported in adult patients, but there are few published pediatric cases (Rusconi et al., 2005). Rusconi et al. (Rusconi et al., 2005) reported that clivus osteomyelitis with an effusive abscess in the retropharyngeal space had been treated by abscess drainage via the posterior wall of the pharyngeal tract and antibiotics therapy. In this case, Rusconi et al. (Rusconi et al., 2005) suggested that this patient may have lacerated the retropharyngeal space with a stick or toy picked up from soil contaminated by Enterococcus (thus allowing the entry of the bacteria and subsequent clivus osteomyelitis).

\subsubsection{Garré's osteomyelitis (chronic sclerosing osteomyelitis)}

Garré's osteomyelitis, first described in 1893, is synonymously used for chronic sclerosing osteomyelitis, periostitis ossificans, and similar forms of osteomyelitis (Braun \& Kreipe, 1979; Wood et al., 1988). Imaging findings in the long bones and jaw have previously been reported, but to our knowledge imaging findings in the skull have been reported in only one case (Klisch et al., 2002).

The calvarium is an uncommon location of sclerosing osteomyelitis, which is still not completely understood. It is assumed that the chronic process is maintained by a slow active infection. The bone responds to stimulation with new bone formation, resorption, or a combination of both. Sclerosis may be the result of either decreased resorption or excessive bone formation. Because sclerosis of the bone and calvarial thickening are the predominant imaging findings, the differential diagnosis includes more sclerotic than lytic lesions in the skull (Klisch et al., 2002). Bacterial infection is thought to reach the calvarium by hematogenous spread, or rarely by direct penetration, but in most cases no bacterial growth is obtained in culture, and radionuclide scans for osteomyelitis may be falsely negative (Tumeh et al., 1986).

The imaging findings are not specific, and a wide range of differential diagnoses have to be considered in calvarial lesions in children (Arana et al., 1996): intraosseous hemangioma, or metabolic diseases, e.g., hyperparathyroidism, Langerhans cell histiocytosis, and anemias. The differential diagnosis furthermore includes neoplasms such as osteoid osteoma, Ewing's sarcoma, intraosseous hyperostotic meningioma, osteoblastic metastasis, or fibrous dysplasia.

Treatment of Garré's osteomyelitis is based on individual decision. A conservative approach with antibiotics therapy may lead to a temporary improvement; however, complete resection of the diseased bone is necessary in order to achieve a permanent cure. Klisch et al. (Klisch et al., 2002) performed an extended frontal and parietal trephination and construction with a titanium implant. 
Sclerosing osteomyelitis of the calvarium has to be included in the differential diagnosis of osteolytic and sclerosing lesions of the skull coinciding with persistent swelling of the head (Klisch et al., 2002).

\subsubsection{Spontaneous cranial osteomyelitis in an otherwise healthy child}

In children, three origins for cranial osteomyelitis appear to dominate: Pott's puffy tumor, skull base osteomyelitis secondary to ear infection, or postsurgical complications. However, on extremely rare occasions, risk factors or etiology may not be ascertained (Arnold et al., 2009). Arnold et al. (Arnold et al., 2009) reported a case of spontaneous cranial osteomyelitis in an otherwise healthy child.

Researchers have proposed several theories regarding the etiology of frontal bone osteomyelitis. In Arnold et al.'s reported case, cultures from the wound grew Streptococcus intermedius, a microaerophilic streptococcus in the milleri group that resides in the mouth, upper respiratory tract, and the gastrointestinal and genitourinary tracts. This patient also had poor dental hygiene. Arnold et al. (Arnold et al., 2009) proposed that an infected tooth could have caused bacteremia either before or after the appearance of the scalp hematoma. The bacteremia then possibly seeded the hematoma, resulting in a subperiosteal abscess, which led to osteomyelitis and then to the epidural abscess.

\subsubsection{Skull osteomyelitis after varicella infection}

Superficial bacterial infection is a well-known complication of varicella infection, but serious superinfection requiring hospitalization and intravenous antibiotic therapy is uncommon (Fleisher et al., 1981). Rarely do these lead to deep-seated, suppurative complications such as osteomyelitis. A 5.5-month-old girl presented with a pox lesion of the scalp associated with a 1-cm-diameter lytic lesion of the right parietal bone (Gallagher, 1990). This lesion was treated by debridement and intravenous antibiotics therapy. Patients with varicella-related superficial bacterial infections should receive close follow-up and, when indicated, antibiotic therapy should be started.

\subsection{Fungal skull osteomyelitis}

Most invasive fungal infections occur in patients with prolonged neutropenia, critically ill patients in intensive care, patients undergoing chemotherapy for solid tumors, patients with acquired immunodeficiency syndrome (AIDS), and patients who have received an organ transplant. A secondary infection by an opportunistic fungus in an already immunocompromised patient is not easy to diagnose or treat, and the prognosis for patients with this life-threatening complication is poor (Safaya et al., 2006).

\subsubsection{Cryptococcal osteomyelitis of the skull}

Cryptococcosis is an opportunistic mycosis caused by members of the Cryptococcus neoformans (C. neoformans) complex. Although it has been known since the beginning of the $20^{\text {th }}$ century when it occasionally affected immunocompetent humans, it has recently become more important because of its association with the human immunodeficiency virus (HIV) epidemic. C. neoformans infections typically involve the lungs and the central nervous 
system, but can also affect other organs, e.g., the skin, eye, prostate, and, rarely, the skeletal system (Chayakulkeeree \& Perfect, 2006).

Cryptococcal osteomyelitis is often preceded by dissemination of the etiologic agent from the portal of entry. Bone involvement is found in $10 \%$ of patients with disseminated disease. Osteomyelitis without fungemia is uncommon, appearing in a little more than 50 reported cases. In addition to systemic infection, cryptococcal osteomyelitis has been typically associated with sarcoidosis, tuberculosis, steroid therapy, and diabetes (Liu, 1998). When bone infections do occur, Cryptococcus is most commonly associated with the vertebrae, pelvis, ribs, femur, and tibia, with one-quarter of patients having involvement of more than one bone (Liu, 1998; Witte et al., 2000). The skull is a less frequent target, with only 18 previously reported cases (Corral et al., 2011).

Cryptococcal osteomyelitis in the skull shares many characteristics with cutaneous cryptococcosis. Direct inoculation after trauma is a common cause, although hematogenous dissemination from adjacent areas of infection is also responsible for many cases of osteomyelitis. Predisposing risk factors are very similar for both entities, i.e., corticosteroid use, solid organ transplantation, diabetes mellitus, and T-cell deficiency (Corral et al., 2011).

Diagnosis was accomplished in all cases through excision biopsy. Smears should be prepared with india ink and Wright's stain. Mucicarmine stains can help distinguish Cryptococcus from other fungal infections (Armonda et al., 1993). The identification of the fungi recovered from patients is accomplished by conventional methods and culture of the isolate on 3,4-dihydroxyphenylalanine (DOPA) agar and canavanine glycine bromothymol blue (CGB) media.

Treatment for cryptococcal skull osteomyelitis includes a combination of surgical debridement and systemic antifungals (Christianson et al., 2003; Corral et al., 2011). If cerebrospinal fluid was sterile, surgical curettage and oral fluconazole without amphotericin B could be a good regimen for treating these cases (Corral et al., 2011). However, amphotericin B should be included in the regimen if meningitis is coincident.

Cryptococcal osteomyelitis of the skull probably has a worse outcome, with a mortality of $16 \%(2 / 12)$ compared with 5\% (2/40) for nonskull osteomyelitis as reported by Liu in 1998 (Liu, 1998).

\subsubsection{Aspergillus infection}

Although human exposure to Aspergillus is common, infections are infrequent. Aspergillus osteomyelitis is often seen in patients who are immunodeficient, taking cytotoxic medications, of advanced age, receiving antimicrobial therapy, or taking chronic systemic steroids (Rinaldi, 1983). Invasive fungal disease is usually caused by A. fumigatus and less commonly by A. flavus (Bickley et al., 1988). In some cases, A. niger was isolated (Shelton et al., 2002). Invasive skull base mastoiditis, also known as malignant or necrotizing otitis externa, typically affects immunocompromised patients and is usually caused by $P$. aeruginosa. Patients with invasive aspergillosis can have similar clinical presentation and physical findings as those with an infection caused by $P$. aeruginosa. Failure to identify Aspergillus as the causative pathogen of invasive temporal bone infection is the principal reason for delay in initiating potentially life-saving therapy. 
Definitive diagnosis of fungal SBO usually requires pathological demonstration of tissue invasion. However, a technetium bone scan is very sensitive for osteomyelitis, and is a strongly positive indicator. Gallium scans are also positive indicators, further supporting the diagnosis of osteomyelitis (Shelton et al., 2002).

Although the ideal treatment for cases of post-traumatic cranial osteomyelitis caused by Aspergillus spp. has not yet been described, the authors of some previously reported cases of MOE affecting the temporal bone used a treatment consisting of surgical debridement of the wound and intravenous long-term treatment with amphotericin B (Gordon \& Giddings, 1994). Therefore, treatment of Aspergillus mastoiditis is threefold. Aggressive surgical debridement and resection is required, and antifungal therapy should be instituted once the diagnosis is made. HBO therapy should be considered postoperatively, although clear evidence to demonstrate its effectiveness is still lacking. Treatment failure could also be the result of suboptimal therapeutic management as a consequence of antifungal agent toxicity. In particular, the side effects of amphotericin B, especially renal failure, may require interruption of antifungal agents or a decrease in dosage (Parize et al., 2009). Parize et al. (Parize et al., 2009) recommended that based on its favorable bone penetration, its tolerance, and its efficacy, voriconazole may be considered an attractive first-line therapeutic option for Aspergillus SBO.

\subsubsection{Blastomycotic skull osteomyelitis}

Blastomycotic cranial osteomyelitis is a rare disease that warrants consideration in persistent otologic infections despite adequate antimicrobial therapy. Temporal bone blastomycotic osteomyelitis is extremely rare and difficult to diagnose, because it appears to present as common serous otitis media. In one case, it was approximately 1 year between the initial presentation and the final diagnosis of blastomycosis (Farr et al., 1992). In another case, it was 5 years between the initial presentation with serous otitis media and the final diagnosis of blastomycosis, despite numerous attempts at fungal stains and cultures (Louis \& Lockey, 1974). Progression of the disease despite antimicrobial therapy should cause consideration of alternative diagnosis such as Mycobacterium tuberculosis, Pseudomonas sp., other fungi, and tumors.

Hematoxylin and eosin staining commonly reveals pseudoepitheliomatous hyperplasia, dense granulomatous infiltration, microabscesses, or giant cells. A relatively unusual pattern of inflammation that is characteristic of this infection is granuloma with central suppuration. A definitive diagnosis requires culture on Sabouraud's agar, or one of the enriched agars such as Sabhi or brain heart infusion, at $30^{\circ} \mathrm{C}$, and reveals a characteristic white mold (Farr et al., 1992).

The mainstay of treatment of blastomycosis is amphotericin B, which has significantly reduced the $60 \%$ mortality rate of the infection since its introduction in the 1950s (Farr et al., 1992).

\subsubsection{Cerebral mycetoma with cranial osteomyelitis}

Mycetoma is a chronic granulomatous infection caused by true fungi (eumycetoma) or bacterial actinomycetes (actinomycetoma). Mycetoma is characterized by the presence of a subcutaneous mass and multiple sinuses draining pus, blood, and fungal grains. Traumatic injury to the local tissue is considered to be its route into the subcutaneous tissue, where 
these saprophytic fungi cause chronic granulomatous inflammation. The infection then spreads through the fascial planes and destroys connective tissue and bone. In the bone, the cortex is invaded and masses of grains gradually replace osseous tissue and marrow. The appearance of various granules on pathological examination is characteristic and allows a specific diagnosis of the causative organism (Beeram et al., 2008).

Mycetoma is clinically manifested by the appearance of painless papules or nodules that swell up and rupture, leading to sinus tract formation. As the infection spreads, similar lesions appear in adjacent skin and soft tissue. The tissue undergoes a recurring cycle of swelling, suppuration, and scarring. Ultimately, the infected site becomes a swollen, deformed mass of destroyed tissue with many fistulas through which grains are discharged (Beeram et al., 2008).

Currently, itraconazole and ketoconazole are the best treatment options. The duration of treatment varies with the severity of the infection and the general health status of individual adults (Welsh et al., 1995). It may be necessary to continue treatment for years, and the liver function of such patients requires regular monitoring. After treatment with itraconazole, these lesions remain well-encapsulated, localized, and easily excisable. Early diagnosis followed by antifungal treatment in combination with surgical excision appears to be a reasonable treatment (Beeram et al., 2008).

\subsubsection{Mucormycosis SBO}

A few reports of chronic invasive mucormycotic sinusitis causing SBO have appeared in the literature (Bahna et al., 1980; Finn \& Farmer, 1982). Mucormycosis is the third most common opportunistic fungal infection in immunocompromised and diabetic patients (Safaya et al., 2006). However, skull base involvement is generally a late and uncommon finding in this situation. More frequently, mucormycosis results in sinonasal, orbital, and deep facial softtissue infiltration and intracranial involvement, cerebral abscesses, and infarcts. The late occurrence of bony involvement is explained by the angioinvasive nature of the fungus and characteristically deep extension of the infection through perivascular channels that precedes frank bony destruction (Gamba et al., 1986). Mucormycotic SBO is rare, but has been described as a late finding.

In the appropriate clinical context, the imaging findings of rhinocerebral mucormycosis on CT and MR imaging are diagnostic (Gamba et al., 1986). These include soft-tissue opacification of sinuses with hyperdense material, nodular mucosal thickening, and an absence of fluid levels (Gamba et al., 1986).

Management of chronic rhinocerebral mucormycosis is not well established. Wide surgical debridement where feasible, prolonged high-dose systemic amphotericin B, control of underlying comorbid factors, and $\mathrm{HBO}$ are used. Survival rates range from $21 \%$ to $70 \%$ (Blitzer et al., 1980).

\subsection{Skull infection in human immunodeficiency virus (HIV)-infected patients}

\subsubsection{MOE in HIV and AIDS}

MOE is a necrotizing infection of the external ear canal that may spread to include the mastoid and petrous parts of the temporal bone, leading to SBO. It is almost exclusively 
caused by infection with $P$. aeruginosa, and usually occurs in elderly non-insulin-dependent diabetic patients. Patients with HIV infection and AIDS are at risk because many take multiple chemotherapeutic medications, including cotrimoxazole, and have defects in both cell-mediated and humoral immunity. Factors contributing to the neutropenia include the effect of the HIV infection itself, administration of zidovudine, toxic effects of other drugs, and bone marrow suppression secondary to opportunistic infections and neoplasia (Kielhofner et al., 1992). Another factor in the susceptibility of HIV and AIDS patients to Pseudomonas infection is the effect of concurrent infection with cytomegalovirus. Cytomegalovirus itself may have immunosuppressive effects and enhance the ability of $P$. aeruginosa to cause disease (Hamilton \& Overall, 1978).

Since the advent of AIDS, several cases of MOE have been reported in afflicted patients. The first published case of MOE was documented in 1990 in an HIV-seropositive Hispanic male (Rivas \& Pumarola, 1990). Sporadic cases of this invasive infection have been reported in HIV and AIDS patients (Chandler, 1989; Kielhofner et al., 1992; Reiss et al., 1991; Scott et al., 1984). None of the patients had underlying diabetes, and all were severely immunocompromised with either markedly decreased CD4 cell counts or neutropenia.

Factors implicated in MOE include preexisting dermatitis of the external ear canal, concurrent medication with antibiotics, recent ear syringing, and immunosuppressive defects.

Treatment should include combination anti-Pseudomonas antibiotic therapy such as ciprofloxacin and ceftazidime. Mendelson et al. (Mendelson et al., 1994), in a study of 27 episodes of Pseudomonas bacteremia in AIDS patients, found that in an analysis of the effect of the number of agents used in the total intravenous course of treatment, mortality was $44.4 \%$ for one agent and $26.7 \%$ for two agents $(p=0.036)$. Thus, the combination of two antimicrobial agents was found to be significantly more beneficial in treating Pseudomonas infection (Hern et al., 1996).

If a patient with HIV and AIDS presents with a history of intense otalgia and purulent otorrhea, a diagnosis of MOE should be considered and appropriate investigations undertaken.

\subsubsection{Salmonella osteomyelitis}

Nontyphoidal salmonella infections are recognized with increasing frequency in HIVinfected individuals. Recurrent bacteremia is the most common manifestation, while localized infections have rarely been described in patients with HIV infection (Sperber \& Schleupner, 1987). It is known that Salmonella organisms can produce local pyogenic infections in any anatomic site (Cohen et al, 1987). Before the AIDS epidemic, suppurative complications were described in about $7 \%$ of salmonellosis cases (Sperber \& Schleupner, 1987). There have been few reports of extraintestinal foci of infection with abscess formation in AIDS patients. However, a location in the bone is rare. Cohen et al. (Cohen et al, 1987) reported 150 cases of osteomyelitis, of which only three were localized in flat bones. Curiously, lesions were localized in flat cranial bones (parietal) in two of them (Mastroianni et al., 1992; Gato et al., 1989). The number of CD4-positive lymphocytes reflects a severe stage of immunocompromisation (Belzunegui et al., 1997). 
One case with cranial Salmonella abscess with parietal bone osteomyelitis in an HIV-infected patient showed good recovery (Mastroianni et al., 1992). The use of an appropriate antibiotic, ciprofloxacin, with a high bactericidal activity against Salmonella and good intracellular penetration, allowed a favorable clinical outcome from the infection without surgical drainage or further complications. The antimicrobial susceptibility of these pathogens in patients with HIV infection does not appear to differ from that in other patients. They should be treated with ampicillin, amoxicillin, a third-generation cephalosporin or ciprofloxacin for 6 weeks or longer, and long-term therapy with an oral antimicrobial may be required in localized forms such as endocarditis or osteomyelitis in an effort to prevent relapse (Belzunegui et al., 1997).

Because bacteremia resulting from Salmonella organisms is common in HIV-infected individuals, it seems likely that more cases of Salmonella arthritis and osteomyelitis will be encountered in the future.

\subsubsection{Mycobacterium osteomyelitis}

Nontuberculous mycobacterial disease is common in patients with AIDS. Disseminated nontuberculous mycobacterium disease is a common problem for patients with advanced AIDS. Mycobacterium avium complex (MAC) accounts for $96 \%$ of reported cases, while Mycobacterium kansasii (M. kansasii) accounts for only 2.9\% (Horsburgh \& Selik, 1989). M. kansasii can cause tenosynovitis and soft-tissue infections. A few cases of skull osteomyelitis caused by M. kansasii have been reported (Weinroth et al., 1994).

Reports have described M. kansasii infections in patients with HIV infections (Valainis et al., 1991); disseminated disease is a common manifestation in these patients. It is also common to have mixed mycobacterial infections, usually including MAC.

Treatment of $M$. kansasii infections in non-HIV-infected patients usually involves administration of isoniazid, rifampin, and ethambutol for a period of 18-24 months. HIVpositive patients have been treated with the same regimen. However, most patients die prior to completion of therapy. Disseminated disease is universally fatal; the mean survival time is $\sim 6$ months from initial diagnosis (Weinroth et al., 1994).

\subsection{Syphilitic osteomyelitis}

Although there was no evidence by serologic test or pathological evaluations, Treponema pallidum (T. pallidum) infection is reported to have existed prior to AD 300 (Gerszten et al., 1998). Syphilis is a chronic systemic infectious disease caused by the spirochete T. pallidum. In acquired syphilitic infection, the organism has an incubation period lasting about 3 weeks, after which the disease exhibits four classically described clinical stages. In the primary stage, infection is characterized by a non-painful skin lesion (chancre) that is usually associated with regional lymphadenopathy and initial bacteremia. A secondary bacteremic or disseminated stage is associated with generalized mucocutaneous lesions, lymphadenopathy, and variable array of clinical findings. Latent syphilis, having no clinical manifestations, is detected only by reactive serologic tests. A late or tertiary stage occurs in up to one-third of untreated patients 10-30 years later, with typical involvement of the ascending aorta and central nervous and skeletal systems (Fenton et al., 2008). 
Syphilitic osteomyelitis of the skull is a destructive bone disease that occurs as a complication of syphilis. Bone and joint involvement is well described in cases of congenital syphilis, but bone involvement is an unusual manifestation of acquired syphilis (Gurland et al., 2001). The incidence of symptomatic syphilitic osteomyelitis among patients with primary and secondary syphilis is quite rare. In a retrospective review of 854 patients who were diagnosed with secondary syphilis, osteomyelitis was found in only two patients $(0.2 \%)$ (Mindel et al., 1989). Destructive bone lesions are rare complications of early-stage syphilis. However, because the clinical presentation is often nonspecific, the diagnosis can be overlooked in the absence of other syphilitic symptoms. Acquired syphilitic osteomyelitis has been described in only a few case reports in the literature (Chung et al., 1994; Gurland et al., 2001; Huang et al., 2007; Kang et al., 2010). Symptomatic bone involvement in association with syphilis is very unusual.

Presentations have varied, but bone pain is routinely found. Lymphadenopathy is also frequently reported. In early-acquired syphilis, the secondary spirochetemia that resulted after primary infection can lead to infection and involvement of the deeper vascular areas of the periosteum with production of perivascular inflammatory infiltrates and highly cellular granulation tissue. The inflammatory process extends into the Haversian canals, with resultant osteitis and osteomyelitis (Ehrlich \& Kricun, 1976). The medullary canals enlarge with increasing osteolysis. With continued inflammation and bone lysis, an irregular macerated appearance of the bone results. New bone formation can occur, sometimes in a prominent manner, typically along the periphery of the lesion (Turk, 1995).

Radiography of affected bones can demonstrate an osteolytic lesion. Pathological examination can demonstrate a plasma cell and lymphocytic perivascular infiltration of the bone and the surrounding tissue (Gurland et al., 2001). Radiologically, it is difficult to distinguish syphilitic osteomyelitis from other radiolucent lesions of the skull, such as eosinophilic granuloma, multiple myeloma, or cystic fibrous dysplasia. MRI can demonstrate marrow space involvement, the periosteal process, and the degree of intracranial extension more completely than CT. MRI findings in acquired syphilitic osteitis of the calvaria showed a focal enhancing calvarial lesion and adjacent soft tissue abnormality in the scalp (Gurland et al., 2001) (Fig. 8).

The differential diagnosis for lytic bone lesions is very extensive. We suggest that a diagnosis of syphilis be considered for at-risk patients with lytic bone lesions. In addition, since osteomyelitis is a manifestation of secondary syphilis, a serum rapid plasma reagin test, or venereal disease research laboratory (VDRL) test, or T. pallidum haemagglutination assay (TPHA) should be sufficient to exclude syphilis as a possibility. The presence of organisms on biopsy material is variably seen and is less common in late-stage disease. One report notes that spirochete visualization by dark field microscopy is present in only $50 \%$ of biopsied cases of bone involvement in early-stage syphilis (Halm, 1979).

Syphilitic osteomyelitis can be treated with antibiotic therapy, benzathine penicillin, or ceftriaxone (Dismukes et al., 1976; Fenton et al., 2008). Although symptomatic relief after therapy is typically rapid, the osseous lesions in early-phase syphilis resolve more slowly and can persist for up to 7-11 months. With proper therapy, there can be complete conventional radiographic and imaging resolution of lesions, with little residual abnormality (Gurland et al., 2001). Early recognition will result in prompt therapy of this treatable condition. 

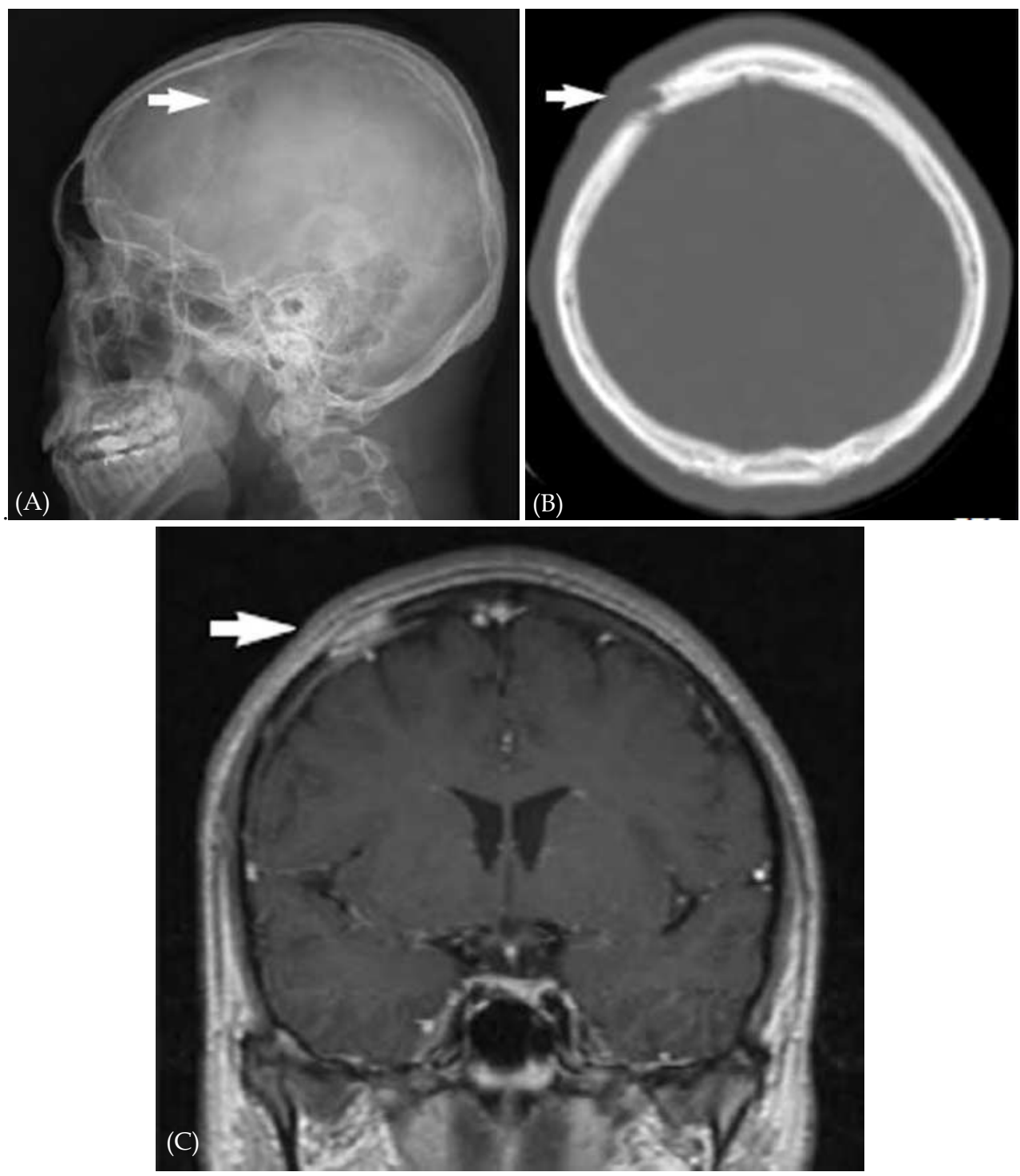

Fig. 8. The imaging study of syphilitic osteomyelitis in a 20 -year-old man. A: Skull lateral X-ray image shows a $17-\mathrm{mm}$ radiolucent skull lesion (arrow) of the parietal bone. B: Computed tomography shows a 17-mm osteolytic skull lesion (arrow) involving the whole thickness of the right parietal bone. C: A coronal magnetic resonance imaging section shows a well-enhanced mass lesion involving the whole thickness of the skull (arrow) at the right parietal area and surrounding soft tissue swelling. (Reproduced with permission from. Kang, SH., Park, SW., Kwon, KY., \& Hong, WJ. (2010). A solitary skull lesion of syphilitic osteomyelitis. J Korean Neurosurg Soc, Vol.48, No.1, (July 2010), pp. 8587, ISSN 2005-3711) (Kang et al., 2010) 


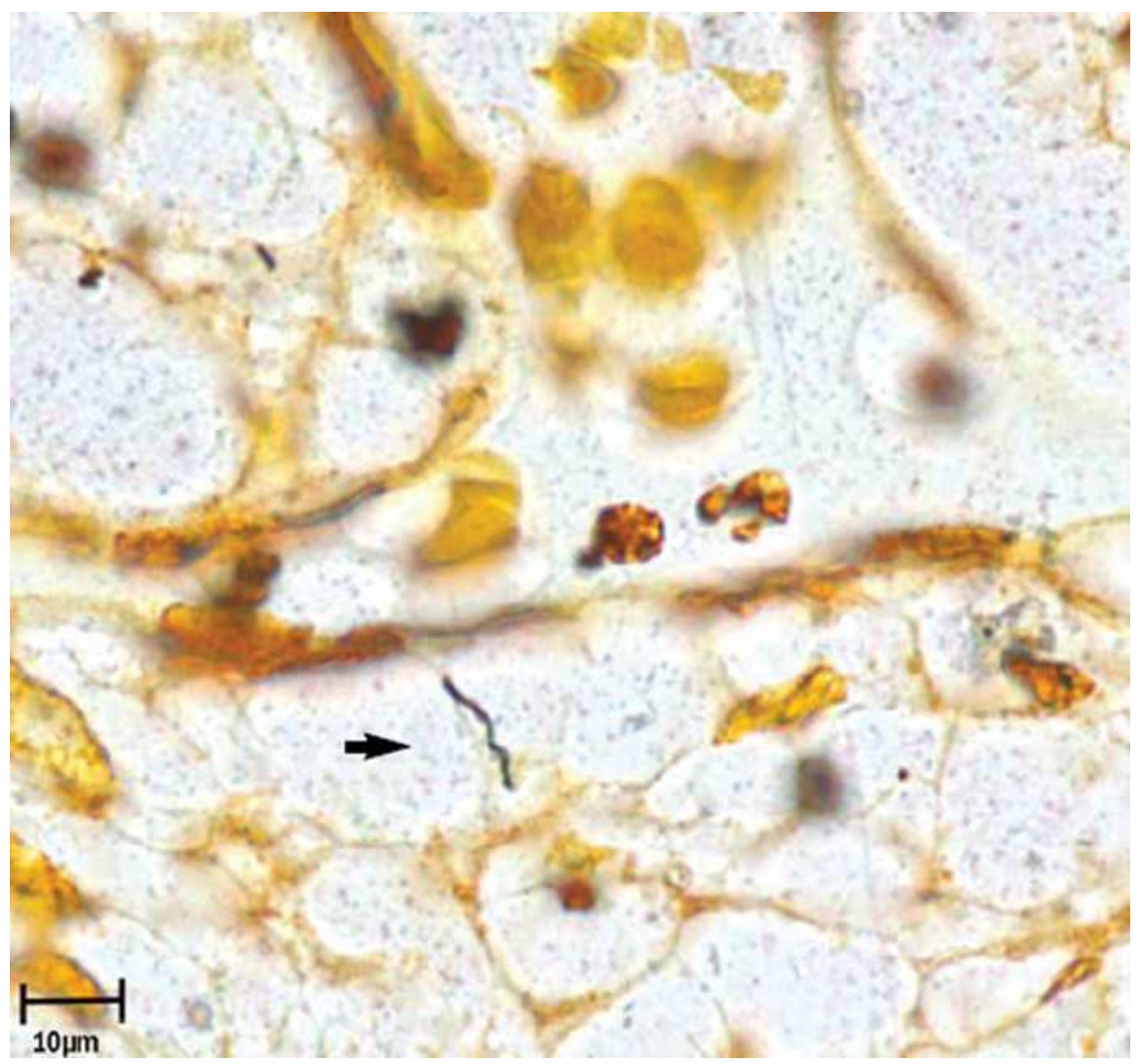

Fig. 9. Identification of spirochetes by Warthin-Starry staining in a skull bone specimen ( $\times 1000)$. Arrow indicates the Treponema pallidum. (Reproduced with permission from. Kang, SH., Park, SW., Kwon, KY., \& Hong, WJ. (2010). A solitary skull lesion of syphilitic osteomyelitis. J Korean Neurosurg Soc, Vol.48, No.1, (July 2010), pp. 85-87, ISSN 2005-3711) (Kang et al., 2010)

\subsection{Tubercular osteomyelitis}

Skull osteomyelitis may also result from infection of the bone by tubercular bacilli (Bhatia et al., 1980). Calvarial tuberculosis is an uncommon form of tuberculosis and is usually seen in younger patients. Most cases reported in the literature are from countries with a high incidence of tuberculosis. The incidence of bone tuberculosis appears to be falling (LeRoux et al., 1990). The overall incidence of skull tuberculosis is approximately $1 / 10,000$ cases of tuberculosis (Davidson \& Horowitz, 1970; Prinsloo \& Kirsten, 1977). Tubercular osteomyelitis is caused by haematogenous or by lymphatic dissemination of bacilli from an active focus, usually in the lungs (Bhatia et al., 1980; Joseph et al., 1989). Many authors have stressed the importance of lymphatics in the spread of tuberculosis. The relative paucity of lymphatics in the cranium has been considered to account for the infrequent tuberculosis infections of the skull bones (Scoggin et al., 1976). 


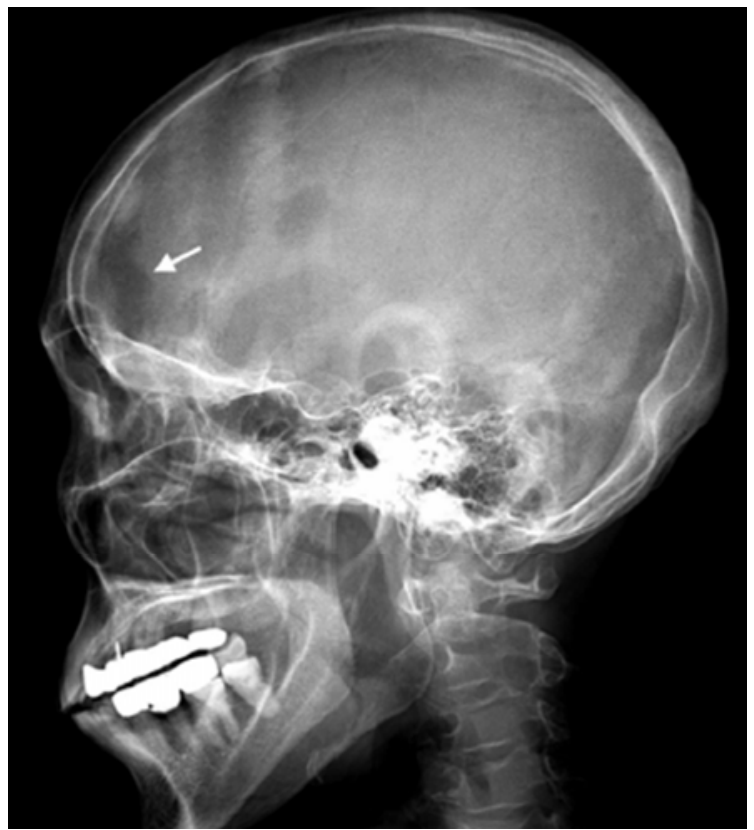

Fig. 10. (A)

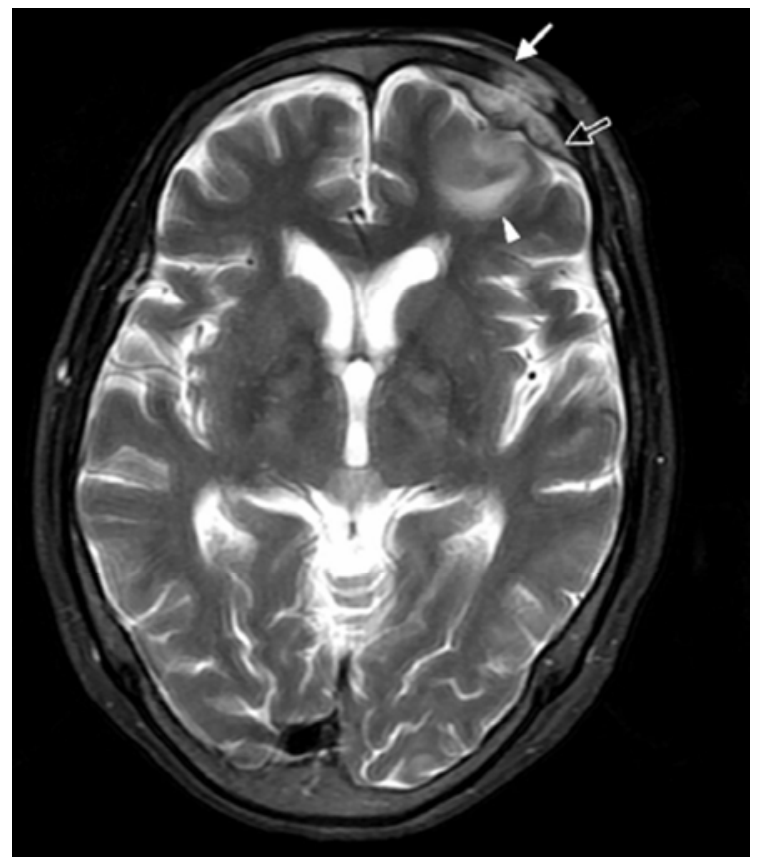

Fig. 10. (B) 


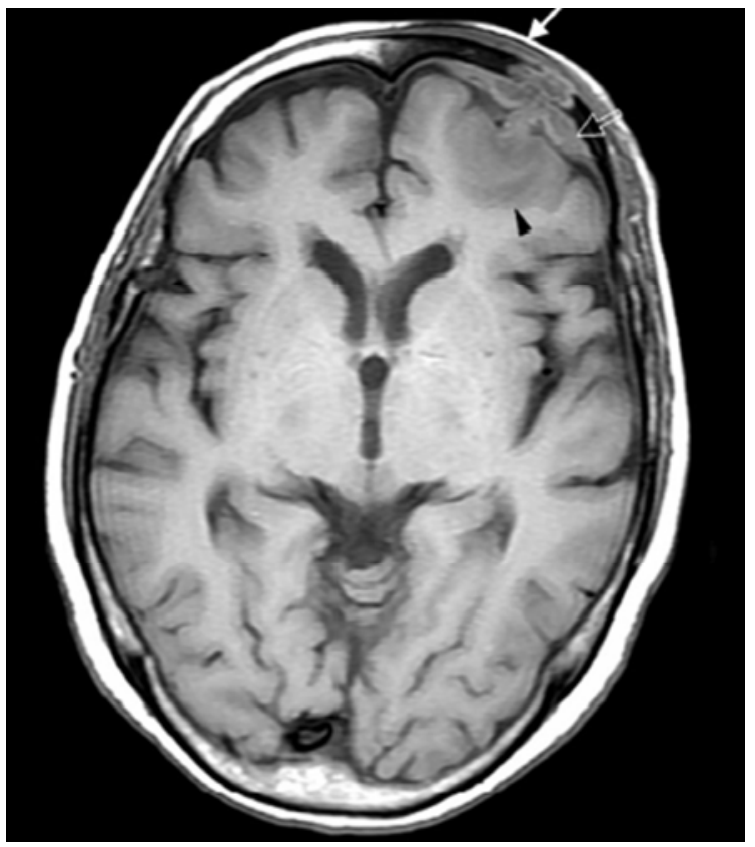

Fig. 10. (C)

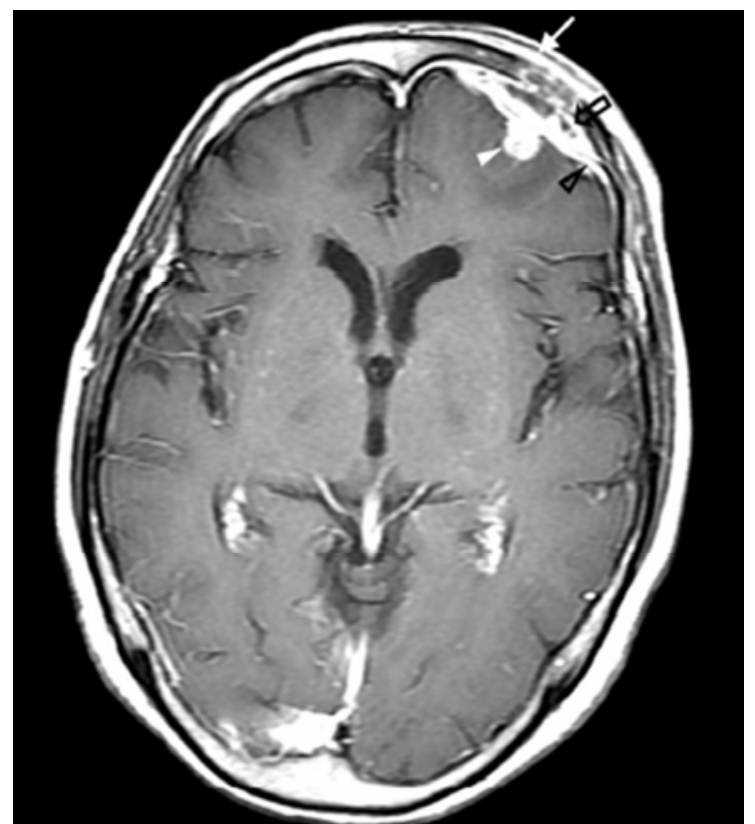

Fig. 10. (D)

Fig. 10. Simple radiography (A) and magnetic resonance imaging (B-D). A: Skull lateral radiography shows the ovoid osteolytic lesion (arrow) without sclerosis in the left frontal 
bone. B. T2-weighted image shows high signal intensity lesions on the left frontal bone diploe, subgaleal space (white arrow), and extradural space (open arrow). High signal intensity is also noted on the left frontal lobe (arrowhead). C. T1-weighted image shows low signal intensity lesions in the left frontal bone and the adjacent frontal lobe. D. Contrastenhanced T1-weighted image shows homogeneous enhancement on the subgaleal space (arrow), peripheral rim enhancement on the extradural space (open arrow), and small nodular enhancement on the right frontal lobe cortex (arrowhead). Thick enhancement along dura (open arrowhead) is also noted. (Reproduced with permission from Kang, M., Cho, JH., Choi, S., Yoon, SK., Kim, KN., \& Lee, JH. (2008). The MRI Findings of Skull Tuberculosis: A Case Report. J Korean Radiol Soc, Vol.58, No.1, (January 2008), pp. 17-20, ISSN 1738-2637) (Kang et al., 2008).

Tuberculosis of the skull is commonly associated with tuberculosis elsewhere in the body. The setting of the bacillus in the diploe marks the onset of acute inflammation surrounded by fibroblasts. Granulation tissue takes place in the bone trabeculae, and Langhans giant cells and epithelioid histiocytes appear (LeRoux et al., 1990). Because the dura is extremely resistant to calvarial tuberculosis, tuberculosis meningitis is rare (LeRoux et al., 1990). With further development, cold abscess formation appears. Tuberculosis of the skull usually appears as a painless mass or ulcer. Systemic manifestations are unusual; headache may occur, but fever is rarely present. Intracranial extension is uncommon, although complications such as tuberculous meningitis or encephalitis have been reported (Scoggin et al., 1976). Clinically, the disease is characterized by lack of early symptoms, and the appearance of fluctuant swelling is usually the first symptom (it is one of the causes of Pott's puffy tumor). The swelling has a soft, fluctuant center with a surrounding firmly attached base, and can thus be differentiated from cephalohematoma. Skin attachment, discoloration, and sinus formation are late features. Headache can occur, but pain localized to the site of the lesion is more common (Malhotra et al., 1993).

Radiologically, tubercular osteomyelitis showed lytic lesions with or without areas of sclerosis. A similar radiological picture may be seen in congenital syphilis, eosinophilic granuloma, or secondary malignant deposits (Bhandari et al., 1981; Bhatia et al., 1980). Radiological findings are nonspecific. The commonest radiological lesion of tubercular osteitis is a single calvarial defect in the frontal or parietal region (Shahat et al., 2004). Both osteolytic and osteoblastic features are seen. Lesions that are usually lytic at first can normally be seen on plain X-ray images of the skull, and are helpful for diagnosis (Schuster et al., 1984). A technetium scan can be helpful to delineate the expansion of the lesion and to rule out meningeal or cerebral involvement.

Cases of tubercular osteomyelitis have been diagnosed on the basis of pathological evaluation of fine needle aspirates and tissue biopsies from the infected bones (Sethi et al., 2008). In all cases, histopathological evaluation has showed epithelioid, caseating granulomas. The presence of caseating granulomas is strongly suggestive of tuberculosis (Bhatia et al., 1980; Joseph et al., 1989). Diagnosis is further supported by positive acid-fast bacilli (AFB) staining, indicating enzyme-linked immunosorbent assay seropositivity for $M$. tuberculosis. Another test that can be used in the diagnosis of tuberculosis is the polymerase chain reaction, which is considered to have a high sensitivity and specificity. The identification of tuberculous bacillus at the site of the lesion confirms the diagnosis (Gupta 
et al., 1989; LeRoux et al., 1990). The differential diagnosis of tuberculosis includes pyogenic osteomyelitis, calvarial metastasis, hemangiomas, aneurismal bone cysts, meningiomas, and histiocytosis (Gupta et al., 1989).

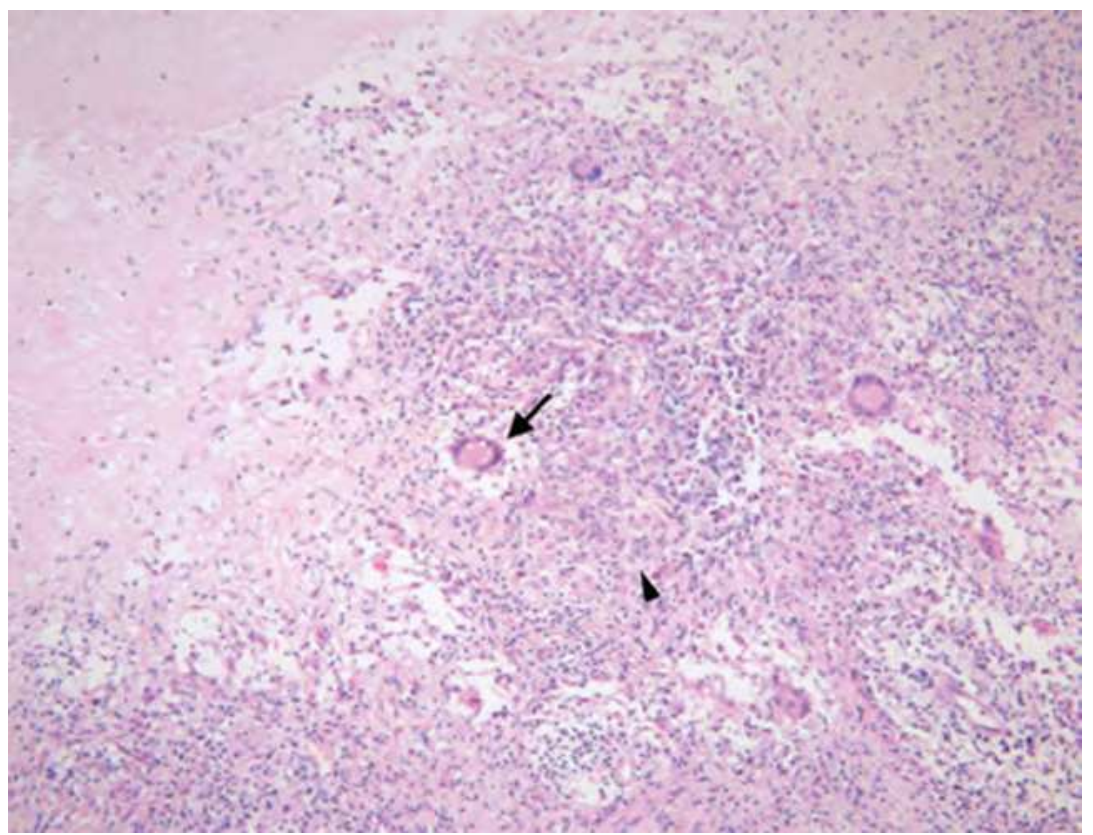

Fig. 11. Microscopic findings (hematoxylin and eosin, $\times 100$ ). Characteristic granuloma composed of central caseous necrosis surrounding epithelioid histiocytes (arrowhead), multinucleated giant cells (arrow), and lymphocytes. The finding is compatible with tuberculosis. (Reproduced with permission from Kang, M., Cho, JH., Choi, S., Yoon, SK., Kim, KN., \& Lee, JH. (2008). The MRI Findings of Skull Tuberculosis: A Case Report. J Korean Radiol Soc, Vol.58, No.1, (January 2008), pp. 17-20, ISSN 1738-2637) (Kang et al., 2008)

The available treatment options are antituberculous chemotherapy and surgery. The role of surgery in the treatment of tuberculous osteomyelitis has declined markedly with the advent of effective antituberculous chemotherapy. Current indications for surgery include the treatment of a subperiosteal abscess and the removal of a sequestrum. Surgical treatment is also considered when the lesion creates a mass effect, when there is an increase in intracranial pressure, or when the patient has a large collection of caseous material (Gupta et al., 1989). However, the treatment of tubercular osteomyelitis is primarily medical, in the form of antituberculous chemotherapy (Sethi et al., 2008).

Tuberculosis of the skull should be suspected in any case of secreting lesions of the scalp that are apparently sterile or fail to respond to conventional antibiotic therapy. It is also important to consider tuberculosis as a cause of postoperative osteomyelitis, as its treatment is quite distinct from pyogenic osteomyelitis, which is the commonest cause of postoperative osteomyelitis. Hence, all bone flaps that are removed for suspected osteomyelitis should be sent for histopathological examination and for AFB and fungal cultures, in addition to 
routine cultures (Biniwale \& Rajshekhar, 2000). Especially in developing countries, tuberculosis should be borne in mind in the differential diagnosis of skull osteomyelitis. Prognosis depends on the gravity of the local disease, but currently, with chemotherapy, it is usually good (Malhotra et al., 1993).

Tuberculosis focused in the calvarium can extend subperiosteally as a swelling under the scalp, and the same lesion could extend into the epidural space as a granuloma. However, an efficient antituberculous regimen and supportive therapy have virtually eliminated such lesions.

\section{Conclusion}

Greater awareness, new diagnostic methods, and better treatment for people with ready access to modern health care have led to a decrease in the rate of treatment failure in acute skull osteomyelitis. Infection control strategies and prophylactic antibiotics have further lowered the rate of postoperative infection. However, skull osteomyelitis has recently become more important because of its association with HIV infection, prolonged neutropenia, critically ill patients in intensive care, chemotherapy for solid tumors, and organ transplant. Early diagnosis, identification of the causative pathogens, prompt initiation of appropriate antimicrobial or surgical therapies, and continuation of therapy for an adequate period are essential when managing skull osteomyelitis. The most important thing in diagnosing skull osteomyelitis is suspicion. Early recognition will result in prompt therapy of this treatable condition.

\section{Acknowledgement}

This work was supported by research grant from an Inje University College of Medicine.

\section{References}

Alexander, JW., Fischer, JE., Boyajian, M., Palmquist, J., \& Morris, MJ. (1983). The influence of hair-removal methods on wound infections. Arch Surg, Vol.118, No.3, (March 1983), pp. 347-352, ISSN 0004-0010

Alva, B., Prasad, KC., Prasad, SC., \& Pallavi, S. (2009). Temporal bone osteomyelitis and temporoparietal abscess secondary to malignant otitis externa. J Laryngol Otol, Vol.123, No.11, (November 2009), pp. 1288-1291, ISSN 0022-2151

Allen, DB., Maguire, JJ., Mahdavian, M., Wicke, C., Marcocci, L., Scheuenstuhl, H., Chang, M., Le, AX., Hopf, HW., \& Hunt, TK. (1997). Wound hypoxia and acidosis limit neutrophil bacterial killing mechanisms. Arch Surg, Vol.132, No.9, (September 1997), pp. 991-996, ISSN 0004-0010

Arana, E., Diaz, C., Latorre, FF., Menor, F., Revert, A., Beltrán, A., \& Navarro, M. (1996). Primary intraosseous meningiomas. Acta Radiol, Vol.37, No.6, (November 1996), pp. 937-942, ISSN 0284-1851

Argenta, LC., \& Morykwas, MJ. (1997). Vacuum-assisted closure: a new method for wound control and treatment: clinical experience. Ann Plast Surg, Vol.38, No.6, (Junuary 1997), pp. 563-577, ISSN 0148-7043 
Armonda, RA., Fleckenstein, JM., Brandvold, B., \& Ondra, SL. (1993). Cryptococcal skull infection: a case report with review of the literature. Neurosurgery, Vol.32, No.6, (June 1993), pp. 1034-1036, ISSN 0148-396X

Arnold, PM., Govindan, S., \& Anderson, KK. (2009). Spontaneous cranial osteomyelitis in an otherwise healthy ten-year-old male. Pediatr Neurosurg, Vol.45, No.6, (2009). pp. 407-409, ISSN 1016-2291

Asai, S., Kamei, Y., \& Torii, S. (2004). One-stage reconstruction of infected cranial defects using a titanium mesh plate enclosed in an omental flap. Ann Plast Surg, Vol.52, No.2, (February 2004), pp. 144-147, ISSN 0148-7043

Azizi, SA., Fayad, PB., Fulbright, R., Giroux, ML., \& Waxman, SG. (1995). Clivus and cervical spinal osteomyelitis with epidural abscess presenting with multiple cranial neuropathies. Clin Neurol Neurosurg, Vol.97, No.3, (August 1995), pp. 239-244, ISSN 0303-8467

Bahna, MS., Ward, PH., \& Konrad, HR. (1980). Nasopharyngeal mucormycotic osteitis: a new syndrome characterized by initial presentation of multiple cranial nerve palsies. Otolaryngol Head Neck Surg, Vol.88, No.2, (March-April 1980), pp. 146-153, ISSN 0194-5998

Bambakidis, NC., \& Cohen, AR. (2001). Intracranial complications of frontal sinusitis in children: Pott's puffy tumor revisited. Pediatr Neurosurg, Vol.35, No.2, (August 2001), pp. 82-89, ISSN 1016-2291

Barker, FG, 2nd. (1994). Efficacy of prophylactic antibiotics for craniotomy: a meta-analysis. Neurosurgery, Vol.35, No.3, (September 1994), pp. 484-492, ISSN 0148-396X

Beeram, V., Challa, S., \& Vannemreddy, P. (2008). Cerebral mycetoma with cranial osteomyelitis. J Neurosurg Pediatr, Vol.1, No.6, (June 2008), pp. 493-495, ISSN 19330707

Belzunegui, J., Lopez, L., Arrizabalaga, J., Gonzalez, C., \& Figueroa, M. (1997). Salmonella osteomyelitis in a patient with human immunodeficiency virus infection. Clin Rheumatol, Vol.16, No.3, (May 1997), pp. 319-320, ISSN 0770-3198

Bhandari, B., Mandowara, SL., \& Joshi, H. (1981). Tubercular osteomyelitis of skull. Indian J Pediatr, Vol.48, No.390, (January-February 1981), pp. 113-115, ISSN 0019-5456

Bhatia, PL., Agarwal, MK., Gupta, OP., \& Khanna, S. (1980). Tubercular osteomyelitis of facial bones. Ear Nose Throat J, Vol.59, No.8, (August 1980), pp. 310-317, ISSN 01455613

Bickley, LS., Betts, RF., \& Parkins, CW. (1988). Atypical invasive external otitis from Aspergillus. Arch Otolaryngol Head Neck Surg, Vol.114, No.9, (September 1988), pp. 1024-1028, ISSN 0886-4470

Biniwale, SN., \& Rajshekhar, V. (2000). Tuberculous osteomyelitis of the bone flap following craniotomy for a glioma. Neurol India, Vol.48, No.1, (March 2000), pp. 91-92, ISSN 0028-3886

Blitzer, A., Lawson, W., Meyers, BR., \& Biller, HF. (1980). Patient survival factors in paranasal sinus mucormycosis. Laryngoscope, Vol.90, No.4, (April 1980), pp. 635648, ISSN 0023-852X

Blomstedt, GC. (1992). Craniotomy infections. Neurosurg Clin N Am, Vol.3, No.2, (April 1992), pp. 375-385, ISSN 1042-3680 
Blyth, CC., Gomes, L., Sorrell, TC., da Cruz, M., Sud, A., \& Chen, SC. (2011). Skull-base osteomyelitis: fungal vs. bacterial infection. Clin Microbiol Infect, Vol.17, No.2, (February 2011), pp. 306-311, ISSN 1198-743X

Braun, OH., \& Kreipe, U. (1979). Rare forms of chronic osteomyelitis in children (author's transl). Klin Padiatr, Vol.191, No.5, (September 1979), pp. 511-521, ISSN 0300-8630

Brook, I. (2009). Microbiology and antimicrobial treatment of orbital and intracranial complications of sinusitis in children and their management. Int J Pediatr Otorhinolaryngol, Vol.73, No.9, (September 2009), pp. 1183-1186, ISSN 0165-5876

Bruce, JN., \& Bruce, SS. (2003). Preservation of bone flaps in patients with postcraniotomy infections. J Neurosurg, Vol.98, No.6, (June 2003), pp. 1203-1207, ISSN 0022-3085

Chamilos, G., Lewis, RE., \& Kontoyiannis, DP. (2008). Delaying amphotericin B-based frontline therapy significantly increases mortality among patients with hematologic malignancy who have zygomycosis. Clin Infect Dis, Vol.47, No.4, (August 2008), pp. 503-509, ISSN 1058-4838

Chan, MS., Wong, YC., Lau, SP., Lau, KY., \& Ou, Y. (2002). MRI and CT findings of infected cephalhaematoma complicated by skull vault osteomyelitis, transverse venous sinus thrombosis and cerebellar haemorrhage. Pediatr Radiol, Vol.32, No.5, (May 2002), pp. 376-379, ISSN 0301-0449

Chandler, JR. (1968). Malignant external otitis. Laryngoscope, Vol.78, No.8, (August 1968), pp. 1257-1294, ISSN 0023-852X

Chandler, JR. (1989). Malignant external otitis and osteomyelitis of the base of the skull. Am J Otol, Vol.10, No.2, (March 1989), pp. 108-110, ISSN 0192-9763

Chandler, JR., Grobman, L., Quencer, R., \& Serafini, A. (1986). Osteomyelitis of the base of the skull. Laryngoscope, Vol.96, No.3, (March 1986), pp. 245-251, ISSN 0023-852X

Chang, HY., Chiu, NC., Huang, FY., Kao, HA., Hsu, CH., \& Hung, HY. (2005). Infected cephalohematoma of newborns: experience in a medical center in Taiwan. Pediatr Int, Vol.47, No.3, (June 2005), pp. 274-277, ISSN 1328-8067

Chang, PC., Fischbein, NJ., \& Holliday, RA. (2003). Central skull base osteomyelitis in patients without otitis externa: imaging findings. AJNR Am J Neuroradiol, Vol.24, No.7, (August 2003), pp. 1310-1316, ISSN 0195-6108

Chayakulkeeree, M., \& Perfect, JR. (2006). Cryptococcosis. Infect Dis Clin North Am, Vol.20, No.3, (September 2006), pp. 507-544, ISSN 0891-5520

Chou, SN., \& Erickson, DL. (1976). Craniotomy infections. Clin Neurosurg, Vol.23, pp. 357362, ISSN 0069-4827

Christianson, JC., Engber, W., \& Andes, D. (2003). Primary cutaneous cryptococcosis in immunocompetent and immunocompromised hosts. Med Mycol, Vol.41, No.3, (June 2003), pp. 177-188, ISSN 1369-3786

Chung, KY., Yoon, J., Heo, JH., Lee, MG., Jang, JW., \& Lee, JB. (1994). Osteitis of the skull in secondary syphilis. J Am Acad Dermatol, Vol.30, No.5 Pt 1, (May 1994), pp. 793-794, ISSN 0190-9622

Cohen, D., \& Friedman, P. (1987). The diagnostic criteria of malignant external otitis. J Laryngol Otol, Vol.101, No.3, (March 1987), pp. 216-221, ISSN 0022-2151

Cohen, JI., Bartlett, JA., \& Corey, GR. (1987). Extra-intestinal manifestations of salmonella infections. Medicine (Baltimore), Vol.66, No.5, (September 1987), pp. 349-388, ISSN 0025-7974 
Corral, JE., Lima, S., Quezada, J., Samayoa, B., \& Arathoon, E. (2011). Cryptococcal osteomyelitis of the skull. Med Mycol, Vol.49, No.6, (August 2011), pp. 667-671, ISSN 1369-3786

Davidson, PT., \& Horowitz, I. (1970). Skeletal tuberculosis. A review with patient presentations and discussion. Am J Med, Vol.48, No.1, (January 1970), pp. 77-84, ISSN 0002-9343

Dismukes, WE., Delgado, DG., Mallernee, SV., \& Myers, TC. (1976). Destructive bone disease in early syphilis. JAMA, Vol.236, No.23, (December 1976), pp. 2646-2648, ISSN 0098-7484

Driscoll, PV., Ramachandrula, A., Drezner, DA., Hicks, TA., \& Schaffer, SR. (1993). Characteristics of cerumen in diabetic patients: a key to understanding malignant external otitis? Otolaryngol Head Neck Surg, Vol.109, No.4, (October 1993), pp. 676679, ISSN 0194-5998

Durur-Subasi, I., Kantarci, M., Karakaya, A., Orbak, Z., Ogul, H., \& Alp, H. (2008). Pott's puffy tumor: multidetector computed tomography findings. J Craniofac Surg, Vol.19, No.6, (November 2008), pp. 1697-1699, ISSN 1049-2275

Ehrlich, R., \& Kricun, ME. (1976). Radiographic findings in early acquired syphilis: case report and cirtical review. AJR Am J Roentgenol, Vol.127, No.5, (November 1976), pp. 789-792, ISSN 0361-803X

Erman, T., Demirhindi, H., Gocer, AI., Tuna, M., Ildan, F., \& Boyar, B. (2005). Risk factors for surgical site infections in neurosurgery patients with antibiotic prophylaxis. Surg Neurol, Vol.63, No.2, (February 2005), pp. 107-113, ISSN 0090-3019

Farr, RC., Gardner, G., Acker, JD., Brint, JM., Haglund, LF., Land, M., Schweitzer, JB., \& West, BC. (1992). Blastomycotic cranial osteomyelitis. Am J Otol, Vol.13, No.6, (November 1992), pp. 582-586, ISSN 0192-9763

Fenton, KA., Breban, R., Vardavas, R., Okano, JT., Martin, T., Aral, S., \& Blower, S. (2008). Infectious syphilis in high-income settings in the 21st century. Lancet Infect Dis, Vol.8, No.4, (April 2008), pp. 244-253, ISSN 1473-3099

Finn, DG., \& Farmer, JC, Jr. (1982). Chronic mucormycosis. Laryngoscope, Vol.92, No.7Pt 1, (July 1982), pp. 761-766, ISSN 0023-852X

Fleisher, G., Henry, W., McSorley, M., Arbeter, A., \& Plotkin, S. (1981). Life-threatening complications of varicella. Am J Dis Child, Vol.135, No.10, (October 1981), pp. 896899, ISSN 0002-922X

Forgie, SE., \& Marrie, TJ. (2008). Pott's puffy tumor. Am J Med, Vol.121, No.12, (December 2008), pp. 1041-1042, ISSN 0002-9343

Froeschner, EH. (1992). Two examples of ancient skull surgery. J Neurosurg, Vol.76, No.3, (March 1992), pp. 550-552, ISSN 0022-3085

Gallagher, PG. (1990). Osteomyelitis of the skull after varicella infection. Clin Pediatr (Phila), Vol.29, No.1, (January 1990), pp. 29, ISSN 0009-9228

Gamba, JL., Woodruff, WW., Djang, WT., \& Yeates, AE. (1986). Craniofacial mucormycosis: assessment with CT. Radiology, Vol.160, No.1, (July 1986), pp. 207-212, ISSN 00338419

Gato, DA., Perez, GV., Ballesteros, MP., \& Gaspar, AVG. (1989). Salmonella osteomyelitis in an AIDS patient. An Med Interna, Vol.6, No.11, (November 1989), pp. 603, ISSN 0212-7199 
Gerszten, PC., Gerszten, E., \& Allison, MJ. (1998). Diseases of the skull in pre-Columbian South American mummies. Neurosurgery, Vol.42, No.5, (May 1998), pp. 1145-1152, ISSN 0148-396X

Gherini, SG., Brackmann, DE., \& Bradley, WG. (1986). Magnetic resonance imaging and computerized tomography in malignant external otitis. Laryngoscope, Vol.96, No.5, (May 1986), pp. 542-548, ISSN 0023-852X

Goodrich, JT. (2005). Landmarks in the history of neurosurgery, In: Principles of neurosurgery $2^{\text {nd }}$ ed, S.S. Rengachary \& R.G. Ellenbogen, (Eds.), pp. 1-37, Elsevier Mosby, ISBN 978-0-7234-3222-7, Philadelphia, PA, U.S.A.

Goodrich, JT., \& Flamm, ES. (2011). Historical overview of neurosurgery, In: Youmans Neurological Surgery $6^{\text {th }}$ ed, H.R. Winn, (Ed.), pp. 3-37, Elsevier Sanuders, ISBN 9781-4160-5316-3, Philadelphia, PA, U.S.A.

Goodwin, MD., Persing, JA., Duncan, CC., \& Shin, JH. (2000). Spontaneously infected cephalohematoma: case report and review of the literature. J Craniofac Surg, Vol.11, No.4, (July 2000), pp. 371-375, ISSN 1049-2275

Gordon, G., \& Giddings, NA. (1994). Invasive otitis externa due to Aspergillus species: case report and review. Clin Infect Dis, Vol.19, No.5. (November 1994), pp. 866-870, ISSN $1058-4838$

Grobman, LR., Ganz, W., Casiano, R., \& Goldberg, S. (1989). Atypical osteomyelitis of the skull base. Laryngoscope, Jul;Vol.99, No.7 Pt 1, (July 1989), pp. 671-676, ISSN 0023$852 X$

Gupta, M., El-Hakim, H., Bhargava, R., \& Mehta, V. (2004). Pott's puffy tumour in a preadolescent child: the youngest reported in the post-antibiotic era. Int J Pediatr Otorhinolaryngol, Vol.68, No.3, (March 2004), pp. 373-378, ISSN 0165-5876

Gupta, PK., Kolluri, VR., Chandramouli, BA., Venkataramana, NK., \& Das, BS. (1989). Calvarial tuberculosis: a report of two cases. Neurosurgery, Vol.25, No.5, (November 1989), pp. 830-833, ISSN 0148-396X

Gurland, IA., Korn, L., Edelman, L., \& Wallach, F. (2001). An unusual manifestation of acquired syphilis. Clin Infect Dis, Vol.32, No.4, (February 2001), pp. 667-669, ISSN 1058-4838

Guyot, LL., Duffy, CB., Guthikonda, M., \& Natarajan, SK. (2006). Epidural abscess, subdural empyema, and brain abscess, In: Atlas of neurosurgical techniques. Brain, L.N. Sekhar \& R.G. Fessler, (Eds.), pp. 975-980, Thieme Medical Publishers, Inc., ISBN 0-86577920-1, New York, NY, U.S.A.

Halm, DE. (1979). Bone lesions in early syphilis, case report. Nebr Med J, Vol.64, No.10, (October 1979), pp. 310-312, ISSN 0091-6730

Hamilton, JR., \& Overall, JC, Jr. (1978). Synergistic infection with murine cytomegalovirus and Pseudomonas aeruginosa in mice. J Infect Dis, Vol.137, No.6, (June 1978), pp. 775-782, ISSN 0022-1899

Hanna, E., Hughes, G., Eliachar, I., Wanamaker, J., \& Tomford, W. (1993). Fungal osteomyelitis of the temporal bone: a review of reported cases. Ear Nose Throat J, Vol.72, No.8, (August 1993), pp. 532, 537-41, ISSN 0145-5613

Hern, JD., Almeyda, J., Thomas, DM., Main, J., \& Patel, KS. (1996). Malignant otitis externa in HIV and AIDS. J Laryngol Otol, Vol.110, No.8, (August 1996), pp. 770-775, ISSN 0022-2151 
Hoistad, DL., \& Duvall AJ, 3rd. (1999). Sinusitis with contiguous abscess involvement of the clivus and petrous apices. Case report. Ann Otol Rhinol Laryngol, Vol.108, No.5, (May 1999), pp. 463-466, ISSN 0003-4894

Horsburgh CR, Jr., \& Selik, RM. (1989). The epidemiology of disseminated nontuberculous mycobacterial infection in the acquired immunodeficiency syndrome (AIDS). Am Rev Respir Dis, Vol.139, No.1, (January 1989), pp. 4-7, ISSN 0003-0805

Hosein, IK., Hill, DW., \& Hatfield, RH. (1999). Controversies in the prevention of neurosurgical infection. J Hosp Infect, Vol.43, No.1, (September 1999), pp. 5-11, ISSN 0195-6701

Huang, I., Leach, JL., Fichtenbaum, CJ., \& Narayan, RK. (2007). Osteomyelitis of the skull in early-acquired syphilis: evaluation by MR imaging and CT. AJNR Am J Neuroradiol, Vol.28, No.2, (February 2007). pp. 307-308, ISSN 0195-6108

Joseph, T., Mishra, HB., \& Singh, JP. (1989). Primary tuberculous osteomyelitis of skull: report of two cases. Br J Neurosurg, Vol.3, No.6, pp. 705-707, ISSN 0268-8697

Kacl, GM., Carls, FR., Moll, C., \& Debatin, JF. (1999). Interactive MR-guided biopsies of maxillary and skull-base lesions in an open-MR system: first clinical results. Eur Radiol, ;Vol.9, No.3, pp. 487-492, ISSN 0938-7994

Kang, M., Cho, JH., Choi, S., Yoon, SK., Kim, KN., \& Lee, JH. (2008). The MRI Findings of Skull Tuberculosis: A Case Report. J Korean Radiol Soc, Vol.58, No.1, (January 2008), pp. 17-20, ISSN 1738-2637

Kang, SH., Park, SW., Kwon, KY., \& Hong, WJ. (2010). A solitary skull lesion of syphilitic osteomyelitis. J Korean Neurosurg Soc, Vol.48, No.1, (July 2010), pp. 85-87, ISSN 2005-3711

Karaman, E., Hacizade, Y., Isildak, H., \& Kaytaz, A. (2008). Pott's puffy tumor. J Craniofac Surg, Vol.19, No.6, (November 2008), pp. 1694-1697, ISSN 1049-2275

Kielhofner, M., Atmar, RL., Hamill, RJ., \& Musher, DM. (1992). Life-threatening Pseudomonas aeruginosa infections in patients with human immunodeficiency virus infection. Clin Infect Dis, Vol.14, No.2, (February 1992), pp. 403-411, ISSN 1058-4838

Klisch, J., Spreer, J., Bötefür, I., Gellrich, NC., Adler, CP., Zentner, J., \& Schumacher, M. (2002). Calvarial sclerosing osteomyelitis. Pediatr Neurosurg, Vol.36, No.3, (March 2002), pp. 128-132, ISSN 1016-2291

Koorbusch, GF., Fotos, P., \& Goll, KT. (1992). Retrospective assessment of osteomyelitis. Etiology, demographics, risk factors, and management in 35 cases. Oral Surg Oral Med Oral Pathol, Vol.74, No.2, (August 1992), pp. 149-154, ISSN 0030-4220

Korinek, AM. (1997). Risk factors for neurosurgical site infections after craniotomy: a prospective multicenter study of 2944 patients. The French Study Group of Neurosurgical Infections, the SEHP, and the C-CLIN Paris-Nord. Service Epidemiologie Hygiene et Prevention. Neurosurgery, Vol.41, No.5, (November 1997), pp. 1073-1081, ISSN 0148-396X

Kountakis, SE., Kemper, JV, Jr., Chang, CY., DiMaio, DJ., \& Stiernberg, CM. (1997). Osteomyelitis of the base of the skull secondary to Aspergillus. Am J Otolaryngol, Vol.18, No.1, (January-February 1997), pp. 19-22, ISSN 0196-0709

Larsson, A., Engstrom, M., Uusijarvi, J., Kihlstrom, L., Lind, F., \& Mathiesen, T. (2002). Hyperbaric oxygen treatment of postoperative neurosurgical infections. Neurosurgery, Vol.50, No.2, (February 2002), pp. 287-296, ISSN 0148-396X 
Leaper, DJ. (1995). Risk factors for surgical infection. J Hosp Infect, Vol.30, (June 1995), pp. Suppl 127-139, ISSN 0195-6701

Lee, S., Hooper, R., Fuller, A., Turlakow, A., Cousins, V., \& Nouraei, R. (2008). Otogenic cranial base osteomyelitis: a proposed prognosis-based system for disease classification. Otol Neurotol, Vol.29, No.5, (August 2008), pp. 666-672, ISSN 15317129

Lee, SS., Son, JY., Lee, JH., \& Kim, OK. (2005). A Case of Invasive Fungal Sinusitis Accompanied with Inflammatory Pseudotumor in Skull Base. Korean J OtolaryngolHead Neck Surg, Vol.48, No.9, (September 2005), pp. 1173-1176, ISSN 1225-035X

Leedom, JM. \& Holtom, PD. (1993). Infectious complications, In: Brain surgery complication avoidance and management, M.L.J. Apuzzo, (Ed.), pp. 127-144, Churchill Livingstone Inc., ISBN 0-443-08709-1, New York, NY, U.S.A.

LeRoux, PD., Griffin, GE., Marsh, HT., \& Winn, HR. (1990). Tuberculosis of the skull--a rare condition: case report and review of the literature. Neurosurgery, Vol.26, No.5, (May 1990), pp. 851-856, ISSN 0148-396X

Lim, HW., Jang, YJ., Lee, BJ., \& Chung, YS. (2006). A Case of Pott's Puffy Tumor as a Complication of Contralateral Frontal Sinusitis. Korean J Otolaryngol-Head Neck Surg, Vol.49, No.1, (January 2006), pp. 109-112, ISSN 1225-035X

Liu, CY., \& Apuzzo, ML. (2003). The genesis of neurosurgery and the evolution of the neurosurgical operative environment: part I-prehistory to 2003. Neurosurgery, Vol.52, No.1, (January 2003), pp. 3-19, ISSN 0148-396X

Liu, PY. (1998). Cryptococcal osteomyelitis: case report and review. Diagn Microbiol Infect Dis, Vol.30, No.1, (January 1998), pp. 33-35, ISSN 0732-8893

Louis T, 3rd., \& Lockey, MW. (1974). Blastomycosis of the middle ear cleft. South Med J, Vol.67, No.12, (December 1974), pp. 1489-1491, ISSN 0038-4348

Mader, JT., Brown, GL., Guckian, JC., Wells, CH., \& Reinarz, JA. (1980). A mechanism for the amelioration by hyperbaric oxygen of experimental staphylococcal osteomyelitis in rabbits. J Infect Dis, Vol.142, No.6, (December 1980), pp. 915-922, ISSN 0022-1899

Malhotra, R., Dinda, AK., \& Bhan, S. (1993). Tubercular osteitis of skull. Indian Pediatr, Vol.30, No.9, (September 1993), pp. 1119-1123, ISSN 0019-6061

Marr, KA., Carter, RA., Crippa, F., Wald, A., \& Corey, L. (2002). Epidemiology and outcome of mould infections in hematopoietic stem cell transplant recipients. Clin Infect Dis, Vol.34, No.7, (April 2002), pp. 909-917, ISSN 1058-4838

Mastroianni, CM., Vullo, V., \& Delia, S. (1992). Cranial Salmonella abscess with parietal bone osteomyelitis in an HIV-infected patient. AIDS, Vol.6, No.7, (July 1992), pp. 749-750, ISSN 0269-9370

Meltzer, PE., \& Keleman, G. (1959). Pyocutaneous osteomyelitis of the temporal bone, mandible, and zygoma. Laryngoscope, Vol.69, pp. 1300-1316, ISSN 0023-852X

Mendelson, DS., Som, PM., Mendelson, MH., \& Parisier, SC. (1983). Malignant external otitis: the role of computed tomography and radionuclides in evaluation. Radiology, Vol.149, No.3, (December 1983), pp. 745-749, ISSN 0033-8419

Mendelson, MH., Gurtman, A., Szabo, S., Neibart, E,, Meyers, BR., Policar, M., Cheung, TW., Lillienfeld, D., Hammer, G., Reddy, S., Choi, K., Hirschman, SZ. (1994). Pseudomonas aeruginosa bacteremia in patients with AIDS. Clin Infect Dis, Vol.18, No.6, (June 1994), pp. 886-895, ISSN 1058-4838 
Miedema, CJ., Ruige, M., \& Kimpen, JL. (1999). Primarily infected cephalhematoma and osteomyelitis in a newborn. Eur J Med Res, Vol.26, No.4(1), (January 1999), pp. 8-10, ISSN 0949-2321

Mindel, A., Tovey, SJ., Timmins, DJ., \& Williams, P. (1989). Primary and secondary syphilis, 20 years' experience. 2. Clinical features. Genitourin Med, Vol.65, No.1, (January 1989), pp. 1-3, ISSN 0266-4348

Mollman, HD., \& Haines, SJ. (1986). Risk factors for postoperative neurosurgical wound infection. A case-control study. J Neurosurg, Vol.64, No.6, (June 1986), pp. 902-906, ISSN 0022-3085

Nam, JR., Kim, MS., Lee, CH., \& Whang, DH. (2008). Linezolid Treatment for Osteomyelitis due to Staphylococcus Epidermidis with Reduced Vancomycin Susceptibility. J Korean Neurosurg Soc, Vol.43, No.6, (June 2008), pp. 307-310, ISSN 2005-3711

Neovius, EB., Lind, MG., \& Lind, FG. (1997). Hyperbaric oxygen therapy for wound complications after surgery in the irradiated head and neck: a review of the literature and a report of 15 consecutive patients. Head Neck, Vol.19, No.4, (July 1997), pp. 315-322, ISSN 1043-3074

Paramore, CG. (1996). Infections of the scalp and osteomyelitis of the skull, In: Neurosurgery $2^{\text {nd }}$ ed, R.H. Wilkins \& S.S. Rengachary, (Eds.), pp. 3317-3331, McGraw-Hill Companies, ISBN 0-07-113545-6, New York, NY, U.S.A.

Parize, P., Chandesris, MO., Lanternier, F., Poirée, S., Viard, JP., Bienvenu, B., Mimoun, M., Méchai, F., Mamzer, MF., Herman, P., Bougnoux, ME., Lecuit, M., \& Lortholary, O. (2009). Antifungal therapy of Aspergillus invasive otitis externa: efficacy of voriconazole and review. Antimicrob Agents Chemother, Vol.53, No.3, (March 2009), pp. 1048-1053, ISSN 0066-4804

Park, MK., Myers, RA., \& Marzella, L. (1992). Oxygen tensions and infections: modulation of microbial growth, activity of antimicrobial agents, and immunologic responses. Clin Infect Dis, Vol.14, No.3, (March 1992), pp. 720-740, ISSN 1058-4838

Prabhu, SP., Zinkus, T., Cheng, AG., \& Rahbar, R. (2009). Clival osteomyelitis resulting from spread of infection through the fossa navicularis magna in a child. Pediatr Radiol, Vol.39, No.9, (September 2009), pp. 995-998, ISSN 0301-0449

Prasad, R., Verma, N., Mishra, OP., \& Srivastava, A. (2011). Osteomyelitis of skull with underlying brain abscess. Indian J Pediatr, Vol.78, No.8, (August 2011), pp. 10051007, ISSN 0019-5456

Prinsloo, JG., \& Kirsten, GF. (1977). Tuberculosis of the skull vault: a case report. S Afr Med J, Vol.19, No.51(8), (February 1977), pp. 248-250, ISSN 0256-9574

Rao, M., Steele, RW., \& Ward, KJ. (2003). A "hickey". Epidural brain abscess, osteomyelitis of the frontal bone, and subcutaneous abscess (pott puffy tumor). Clin Pediatr (Phila), Vol.42, No.7, (September 2003), pp. 657-660, ISSN 0009-9228

Reiss, P., Hadderingh, R., Schot, LJ., \& Danner, SA. (1991). Invasive external otitis caused by Aspergillus fumigatus in two patients with AIDS. AIDS, Vol.5, No.5, (May 1991), pp. 605-606, ISSN 0269-9370

Rinaldi, MG. (1983). Invasive aspergillosis. Rev Infect Dis, Vol.5, No.6, (November-December 1983), pp. 1061-1077, ISSN 0162-0886

Rivas, Lacarte MP, \& Pumarola, SF. (1990). Malignant otitis externa and HIV antibodies. A case report. An Otorrinolaringol Ibero Am, Vol.17, No.5, pp. 505-512, ISSN 0303-8874 
Roden, MM., Zaoutis. TE., Buchanan, WL., Knudsen, TA., Sarkisova, TA., Schaufele, RL., Sein, M., Sein, T., Chiou, CC., Chu, JH., Kontoyiannis, DP., \& Walsh, TJ. (2005). Epidemiology and outcome of zygomycosis: a review of 929 reported cases. Clin Infect Dis, Vol.1, No.41(5), (September 2005), pp. 634-653, ISSN 1058-4838

Rothholtz, VS., Lee, AD., Shamloo, B., Bazargan, M., Pan, D., \& Djalilian, HR. (2008). Skull base osteomyelitis: the effect of comorbid disease on hospitalization. Laryngoscope, Vol.118, No.11, (November 2008), pp. 1917-1924, ISSN 0023-852X

Rubin, GJ., Branstetter, BFt., \& Yu, VL. (2004). The changing face of malignant (necrotising) external otitis: clinical, radiological, and anatomic correlations. Lancet Infect Dis, Vol.4, No.1, (January 2004), pp. 34-39, ISSN 1473-3099

Rubin, J., Curtin, HD., Yu, VL., \& Kamerer, DB. (1990). Malignant external otitis: utility of CT in diagnosis and follow-up. Radiology, Vol.174, No.2, (February 1990), pp. 391394, ISSN 0033-8419

Rusconi, R., Bergamaschi, S., Cazzavillan, A., \& Carnelli, V. (2005). Clivus osteomyelitis secondary to Enterococcus faecium infection in a 6-year-old girl. Int J Pediatr Otorhinolaryngol, Vol.69, No.9, (September 2005), pp. 1265-1268, ISSN 0165-5876

Safaya, A., Batra, K., \& Capoor, M. (2006). A case of skull base mucormycosis with osteomyelitis secondary to temporal bone squamous cell carcinoma. Ear Nose Throat J, Vol.85, No.12, (December 2006), pp. 822-824, ISSN 0145-5613

Schuster, JD., Rakusan, TA., Chonmaitree, T., \& Box, QT. (1984). Tuberculous osteitis of the skull mimicking histiocytosis X. J Pediatr, Vol.105, No.2, (August 1984), pp. 269-271, ISSN 0022-3476

Scoggin, CH., Schwarz, MI., Dixon, BW., \& Durrance, JR. (1976). Tuberculosis of the skull. Arch Intern Med, Vol.136, No.10, (October 1976), pp. 1154-1156, ISSN 0003-9926

Scott, GB., Buck, BE., Leterman, JG., Bloom, FL., \& Parks, WP. (1984). Acquired immunodeficiency syndrome in infants. N Engl J Med, Vol.12, No.310(2), (January 1984), pp. 76-81, ISSN 0028-4793

Seabold, JE., Simonson, TM., Weber, PC., Thompson, BH., Harris, KG., Rezai, K., Madsen, MT., \& Hoffman, HT. (1995). Cranial osteomyelitis: diagnosis and follow-up with In-111 white blood cell and Tc-99m methylene diphosphonate bone SPECT, CT, and MR imaging. Radiology, Vol.196, No.3, (September 1995), pp. 779-788, ISSN 0033-8419

Sethi, A., Sethi, D., Agarwal, AK., Nigam, S., \& Gupta, A. (2008). Tubercular and chronic pyogenic osteomyelitis of cranio-facial bones: a retrospective analysis. J Laryngol Otol, Vol.122, No.8, (August 2008), pp. 799-804, ISSN 0022-2151

Shahat, AH., Rahman, NU., Obaideen, AM., Ahmed, I., \& Zahman, AA. (2004). Cranialepidural tuberculosis presenting as a scalp swelling. Surg Neurol, Vol.61, No.5, (May 2004), pp. 464-467, ISSN 0090-3019

Shelton, JC., Antonelli, PJ., \& Hackett, R. (2002). Skull base fungal osteomyelitis in an immunocompetent host. Otolaryngol Head Neck Surg, Vol.126, No.1, (January 2002), pp. 76-78, ISSN 0194-5998

Sperber, SJ., \& Schleupner, CJ. (1987). Salmonellosis during infection with human immunodeficiency virus. Rev Infect Dis, Vol.9, No.5, (September-October 1987), pp. 925-934, ISSN 0162-0886 
Sreepada, GS., \& Kwartler, JA. (2003). Skull base osteomyelitis secondary to malignant otitis externa. Curr Opin Otolaryngol Head Neck Surg, Vol.11, No.5, (October 2003), pp. 316-323, ISSN 1068-9508

Stodulski, D., Kowalska, B., \& Stankiewicz, C. (2006). Otogenic skull base osteomyelitis caused by invasive fungal infection. Case report and literature review. Eur Arch Otorhinolaryngol, Vol.263, No.12, (December 2006), pp. 1070-1076, ISSN 0937-4477

Subotic, U., Kluwe, W., \& Oesch, V. (2011). Community-associated methicillin-resistant Staphylococcus aureus-infected chronic scalp wound with exposed dura in a 10year-old boy: vacuum-assisted closure is a feasible option: case report. Neurosurgery, Vol.68, No.5, (May 2011), pp. E1481-1484, ISSN 0148-396X

Tattersall, R. (2002). Pott's puffy tumour. Lancet, Vol.23, No.359(9311), (March 2002), pp. 1060-1063, ISSN 0140-6736

Tumeh, SS., Aliabadi, P., Weissman, BN., \& McNeil, BJ. (1986). Chronic osteomyelitis: bone and gallium scan patterns associated with active disease. Radiology, Vol,158, No.3, (March 1986), pp. 685-688, ISSN 0033-8419

Turk, JL. (1995). Syphilitic caries of the skull--the changing face of medicine. J R Soc Med, Vol.88, No.3, (March 1995), pp. 146-148, ISSN 0141-0768

Valainis, GT., Cardona, LM., \& Greer, DL. (1991). The spectrum of Mycobacterium kansasii disease associated with HIV-1 infected patients. J Acquir Immune Defic Syndr, Vol.4, No.5, pp. 516-520, ISSN 1525-4135

Van Lente, F. (1982). The diagnostic utility of C-reactive protein. Hum Pathol, Vol.13, No.12, (December 1982), pp. 1061-1063, ISSN 0046-8177

Vogelsang, JP., Wehe, A., \& Markakis, E. (1998). Postoperative intracranial abscess--clinical aspects in the differential diagnosis to early recurrence of malignant glioma. Clin Neurol Neurosurg, Vol.100, No.1, (March 1998), pp. 11-14, ISSN 0303-8467

Vourexakis, Z., Kos, MI., \& Guyot, JP. (2010). Atypical presentations of malignant otitis externa. J Laryngol Otol, Vol.124, No.11, (November 2010), pp. 1205-1208, ISSN 0022-2151

Weinroth, SE, Pincetl, P., \& Tuazon, CU. (1994). Disseminated Mycobacterium kansasii infection presenting as pneumonia and osteomyelitis of the skull in a patient with AIDS. Clin Infect Dis, Vol.18, No.2, (February 1994), pp. 261-262, ISSN 1058-4838

Welsh, O., Salinas, MC., \& Rodriguez, MA. (1995). Treatment of eumycetoma and actinomycetoma. Curr Top Med Mycol, Vol.6, pp. 47-71, ISSN 0177-4204

Witte, DA., Chen, I., Brady, J., Ramzy, I., Truong, LD., \& Ostrowski, ML. (2000). Cryptococcal osteomyelitis. Report of a case with aspiration biopsy of a humeral lesion with radiologic features of malignancy. Acta Cytol, Vol.44, No.5, (SeptemberOctober 2000), pp. 815-818, ISSN 0001-5547

Wood, RE., Nortje, CJ., Grotepass, F., Schmidt, S., \& Harris, AM. (1988). Periostitis ossificans versus Garre's osteomyelitis. Part I. What did Garre really say? Oral Surg Oral Med Oral Pathol, Vol.65, No.6, (June 1988), pp. 773-777, ISSN 0030-4220

Yucel, OT., \& Ogretmenoglu, O. (1998). Subdural empyema and blindness due to cavernous sinus thrombosis in acute frontal sinusitis. Int J Pediatr Otorhinolaryngol, Vol.15, No.46(1-2), (November 1998), pp. 121-125, ISSN 0165-5876 


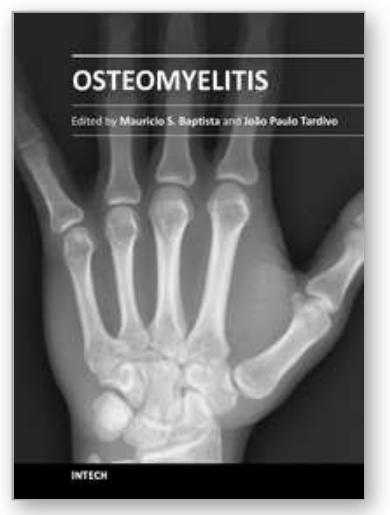

\author{
Osteomyelitis \\ Edited by Prof. Mauricio S. Baptista
}

ISBN 978-953-51-0399-8

Hard cover, 180 pages

Publisher InTech

Published online 23, March, 2012

Published in print edition March, 2012

If you want to learn more about osteomyelitis you should not miss this book. The editors are professionals and scientists working in health sciences and the chapters have been prepared by experts in the field, covering subjects related with the fundamentals of osteomyelitis and new diagnosis and treatment tools. You will have the opportunity to review concepts as well as to learn state-of-the-art alternatives for diagnosis and treatments.

\title{
How to reference
}

In order to correctly reference this scholarly work, feel free to copy and paste the following:

Myoung Soo Kim (2012). Skull Osteomyelitis, Osteomyelitis, Prof. Mauricio S. Baptista (Ed.), ISBN: 978-95351-0399-8, InTech, Available from: http://www.intechopen.com/books/osteomyelitis/skull-osteomyelitis

\section{INTECH}

open science | open minds

\section{InTech Europe}

University Campus STeP Ri

Slavka Krautzeka 83/A

51000 Rijeka, Croatia

Phone: +385 (51) 770447

Fax: +385 (51) 686166

www.intechopen.com

\section{InTech China}

Unit 405, Office Block, Hotel Equatorial Shanghai

No.65, Yan An Road (West), Shanghai, 200040, China

中国上海市延安西路65号上海国际贵都大饭店办公楼405单元

Phone: +86-21-62489820

Fax: +86-21-62489821 
(C) 2012 The Author(s). Licensee IntechOpen. This is an open access article distributed under the terms of the Creative Commons Attribution 3.0 License, which permits unrestricted use, distribution, and reproduction in any medium, provided the original work is properly cited. 